\title{
Revisão de crenças em ACTL usando verificação de modelos limitada
}

\author{
Bruno Vercelino da Hora
}

\author{
DissERTAÇÃO APRESENTADA \\ $\mathrm{AO}$ \\ Instituto DE MATEMÁticA E EstatísticA \\ DA \\ Universidade DE SÃo PaUlo \\ PARA \\ OBTENÇÃO DO TÍTULO \\ $\mathrm{DE}$ \\ Mestre em CiÊnCIAS
}

Programa: Ciência da Computação

Orientador: Prof. Dr. Marcelo Finger

Durante o desenvolvimento deste trabalho o autor recebeu auxílio financeiro da CAPES

São Paulo, setembro de 2017 


\section{Revisão de Crenças em ACTL usando Verificação de Modelos Limitada}

Esta dissertação contem as correções e alterações sugeridas pela Comissão Julgadora durante a defesa realizada por (Bruno Vercelino da Hora) em 03/08/2017.

$\mathrm{O}$ original encontra-se disponivel no Instituto de Matemática e Estatística da Universidade de São Paulo.

Comissão Julgadora:

- Profa. Dr. Marcelo Finger (orientador) - IME-USP

- Prof. Dra. Renata Wassermann - IME-USP

- Prof. Dr. Paulo de Tarso Guerra - UFC 


\section{Agradecimentos}

Acima de tudo agradeço a Deus meu criador e pai que tem cuidado de mim a todo momento, à Jesus meu Senhor e Salvador que morreu em meu lugar para me dar a vida eterna e ao Espírito Santo meu conselheiro e consolador que tem me ensinado e ajudado a caminhar todo dia.

Agradeço a meus pais, Liliam e Eduardo, os quais me apoiam e tem me sustentado a vida toda. Sem vocês eu não teria conquistado nada e esse trabalho é fruto do esforço e investimento de vocês. Agradeço à minha esposa Pâmela, que sempre me apoiou e não me deixou desistir em momento algum. Obrigado por cuidar de mim e fazer minha vida melhor.

Agradeço ao meu professor e orientador Marcelo Finger, pela ajuda, atenção e conselhos durante todos esses últimos anos. Foi uma longa jornada, mas de grande aprendizado, obrigado pela paciência e colaboração. Um agradecimento especial à professora Renata Wasserman que me ajudou bastante com o trabalho, uma parte importante dele saiu de uma boa conversa com ela.

Agradeço ao Instituto de Matemática e Estatística pela instrução recebida durante este mestrado, e à CAPES que financiou este trabalho, permitindo que eu me dedicasse a ele.

Por fim agradeço à todos os meus amigos que sempre me apoiaram e me ajudaram durante todos estes anos. vocês me animaram e me deram descanso quando me preocupava ou estava cansado, e me ajudaram a perseverar e terminar este trabalho. 


\section{Resumo}

Uma importante etapa do desenvolvimento de software é o de levantamento e análise dos requisitos. Porém, durante esta etapa podem ocorrer inconsistências que prejudicarão o andamento do projeto. Além disso, após finalizada a especificação, o cliente pode querer acrescentar ou modificar as funcionalidades do sistema. Tudo isso requer que a especificação do software seja revista, mas isso é altamente custoso, tornando necessário um processo automatizado para simplificar tal revisão. Para lidar com este problema, uma das abordagens utilizadas tem sido o processo de Revisão de Crenças, juntamente com o processo de Verificação de Modelos.

O objetivo deste trabalho é utilizar o processo de revisão de crenças e verificação de modelos para avaliar especificações de um projeto procurando inconsistências, utilizando o fragmento universal daComputation Tree Logic (CTL), conhecido como ACTL, e revisá-las gerando sugestões de mudanças na especificação.

A nossa proposta é traduzir para lógica clássica tanto o modelo (especificação do software) quanto a propriedade a ser revisada, e então aplicar um resolvedor SAT para verificar a satisfazibilidade da fórmula gerada. A partir da resposta do resolvedor SAT, iremos gerar sugestões válidas de mudanças para a especificação, fazendo o processo de tradução reversa da lógica clássica para o modelo original.

Palavras-chave: Revisão de Crenças, CTL, Verificação de Modelos Limitada. 


\section{Abstract}

The objective of this work is to join the proccess of belief revision and model checking to evaluate project specifications looking for inconsistences, using the universal fragment of Computation Tree Logic (CTL), known as ACTL, and revise them generating changes suggestions in the specification.

Our approach will translate the model (software specification) and the property to be revised to classical logic. Then we will apply a SAT solver to verify the generated formula's satsifability. From the SAT solver answer, we will create changes valid suggestions to the specification making the translation back from classical logic to the original model.

To generate the changes suggestions, we proposed a framework based on heuristics where different approaches and decisions can be implemented, aiming a better application for each project scope. We implemented a basic heuristic as an example and used it to test the implementation to analise the proposed algorithm.

Keywords: belief revision, CTL, bounded model checking. 


\section{Sumário}

$\begin{array}{ll}\text { Lista de Figuras } & \text { ix }\end{array}$

1 Introdução $\quad 1$

1.1 Motivação . . . . . . . . . . . . . . . . . . . . . . . . . . . . . . . . . . . .

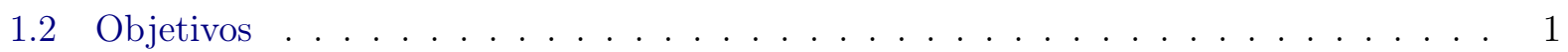

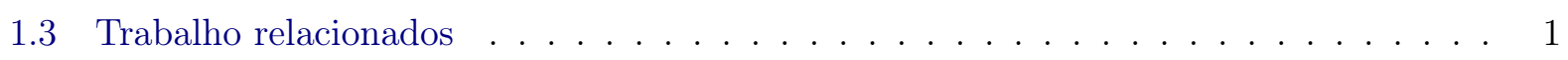

1.4 Apresentação de um exemplo . . . . . . . . . . . . . . . . . . . . . . . . 2

1.5 Organização do trabalho . . . . . . . . . . . . . . . . . . . 3

2 Conceitos básicos $\quad 5$

2.1 Estrutura de Kripke . . . . . . . . . . . . . . . . . . . . . . . . . 5

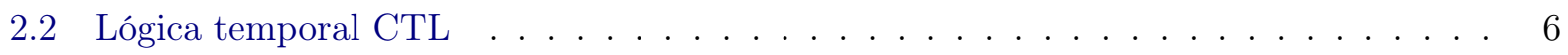

2.2 .1 Sintaxe e Semântica . . . . . . . . . . . . . . . . . . . . . 6

2.2 .2 Tipos de Propriedades . . . . . . . . . . . . . . . . . . 8

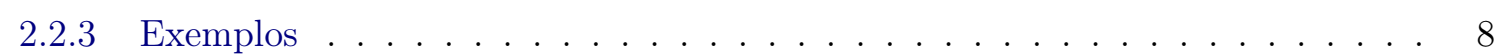

2.3 Verificação de modelos . . . . . . . . . . . . . . . . . . . . . 9

2.3 .1 Verificação de modelos simbólica . . . . . . . . . . . . . . . . . . . . . 9

2.3 .2 Verificação de modelos limitada . . . . . . . . . . . . . . . . . . . . . . 10

2.4 Revisão de crenças . . . . . . . . . . . . . . . . . . . . . . . . . . . . 11

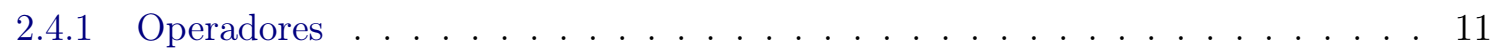

2.4 .2 Representação . . . . . . . . . . . . . . . . . . . . . . . . . . 11

2.4 .3 Postulados . . . . . . . . . . . . . . . . . . . . . . . . . 12

2.4 .4 Revisão versus Contração . . . . . . . . . . . . . . . . . . . . . . . . 13

2.4.5 Indecidibilidade de uma contração em lógicas temporais . . . . . . . . . . . 13

3 Revisão de crenças temporais com verificação de modelos limitada 15

3.1 Algoritmo . . . . . . . . . . . . . . . . . . . . . . . . 16

3.1 .1 Tradução inicial . . . . . . . . . . . . . . . . . . . . . . . 17

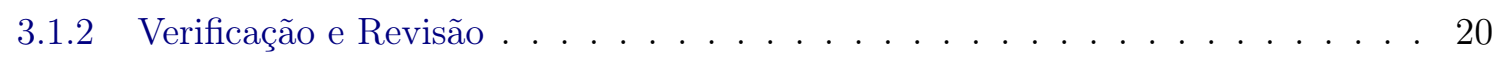

3.1 .3 Tradução reversa . . . . . . . . . . . . . . . . . . . . . . . . . . . . 21

3.1.4 Verificação final e iteração no tamanho dos caminhos . . . . . . . . . . . . . . 22

3.2 Algoritmo de escolha . . . . . . . . . . . . . . . . . . . . . . . . 23

3.2 .1 Necessidade de uma heurística . . . . . . . . . . . . . . . . . . 23

3.2 .2 Definição de uma heurística . . . . . . . . . . . . . . . . . . . . . 24

3.2 .3 Exemplo de heurística . . . . . . . . . . . . . . . . . 25 
3.2 .4 Processo de revisão . . . . . . . . . . . . . . . . . . . . 25

3.2.5 Limitações do uso de heurísticas . . . . . . . . . . . . . . . . . . 26

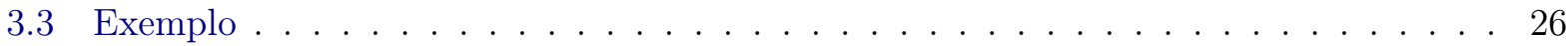

3.4 Indecidibilidade e limitações da abordagem $\ldots \ldots \ldots \ldots$. . . . . . . . . . . . . 29

4 Implementação e aplicação ao exemplo $\quad 31$

4.1 Implementação do algoritmo . . . . . . . . . . . . . . . . . . . . . . . . . . 31

4.1 .1 Entrada . . . . . . . . . . . . . . . . . . . . . . 32

4.1 .2 Tradução e verificação inicial . . . . . . . . . . . . . . . . . . . . . . 34

4.1 .3 Tradução reversa, contração e verificação final . . . . . . . . . . . . . . . . . . 34

4.1 .4 Heurísticas . . . . . . . . . . . . . . . . . . . . . . 36

$5 \quad$ Experimentos e análise $\quad 37$

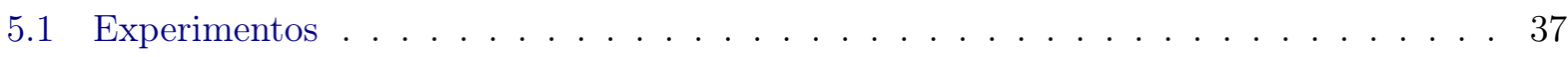

5.1 .1 Exemplo básico . . . . . . . . . . . . . . . . . . . . 37

5.1 .2 Máquina de busca . . . . . . . . . . . . . . . . . . . . 37

5.1 .3 LCS (The Light Control System) . . . . . . . . . . . . . . . . . . . . 39

5.2 Análise da performance . . . . . . . . . . . . . . . . . . 41

5.2 .1 Tamanho da fórmula . . . . . . . . . . . . . . . . . . . . . 41

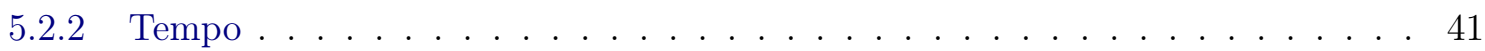

5.2 .3 Sugestões . . . . . . . . . . . . . . . . . . . . . . . . . . 41

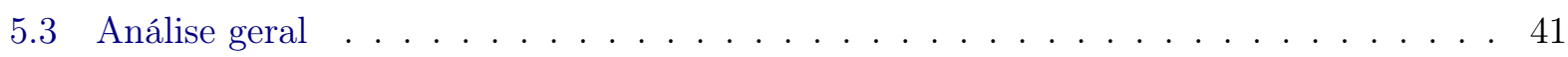

5.3 .1 Restrições . . . . . . . . . . . . . . . . . . . . . 42

6 Conclusões $\quad 45$

6.1 Considerações finais . . . . . . . . . . . . . . . . . . . . . . . 45

6.2 Trabalhos futuros . . . . . . . . . . . . . . . . . . . . 46

$\begin{array}{ll}\text { Referências Bibliográficas } & 47\end{array}$ 


\section{Lista de Figuras}

2.1 Estrutura de Kripke . . . . . . . . . . . . . . . . . . . . . . . 5

2.2 Um caminho da estrutura representada na Figura $2.1 \ldots \ldots \ldots$. . . . . . . . . . 5

2.3 Máquina de busca . . . . . . . . . . . . . . . . . 6

2.4 Operadores temporais da CTL $\ldots \ldots \ldots \ldots \ldots \ldots \ldots$

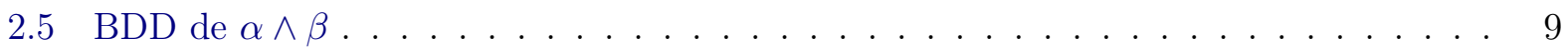

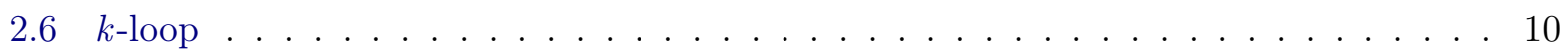

3.1 Verificação de modelos com revisão de crenças . . . . . . . . . . . . . . . . . . . . 15

3.2 Revisão de crenças com verificação de modelos limitada (Finger e Wassermann, 2008) 16

3.3 Representação do algoritmo de revisão de crenças com BMC . . . . . . . . . . . . . . . 17

3.4 Verificação de modelos limitada requisitando revisão de crenças (Finger e Wassermann,

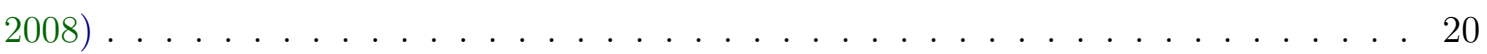

3.5 Variáveis utilizadas para gerar as sugestões . . . . . . . . . . . . . . . . . 21

3.6 Exemplo de limitação $\ldots \ldots \ldots$. . . . . . . . . . . . . . . . . . . . . . 26

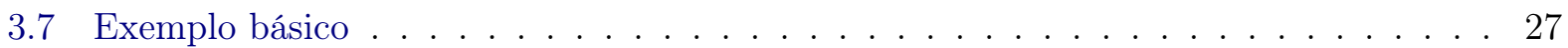

3.8 Primeira verificação . . . . . . . . . . . . . . . . . . . . . . . . . . . . . 28

3.9 Resultado após a primeira mudança . . . . . . . . . . . . . . . . . . 28

3.10 Segunda verificação . . . . . . . . . . . . . . . . . . . . . . . . . 28

3.11 Inserção da propriedade $a \ldots \ldots \ldots \ldots$

4.1 Diagrama de classes . . . . . . . . . . . . . . . . . . . . . 31

4.2 Fluxograma simplificado . . . . . . . . . . . . . . . . . . . . 32

5.1 Estrutura de Kripke para o exemplo . . . . . . . . . . . . . . . . . . . . . . . 37

5.2 Máquina de busca . . . . . . . . . . . . . . . . . . . 38

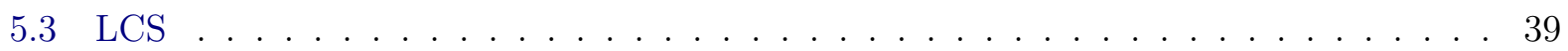




\section{Capítulo 1}

\section{Introdução}

\subsection{Motivação}

Uma das etapas do desenvolvimento de software é o levantamento e análise de requisitos. Nela são investigadas as funcionalidades necessárias e desejadas do software, e neste processo qualquer erro, inconsistência ou esquecimento quando detectado em uma fase posterior do desenvolvimento pode acarretar em mudanças em todo o projeto, atrasando a entrega e tornando-o mais custoso. Na prática é impossível conseguir evitar tais reajustes, devido à dificuldade de avaliar o conjunto de requisitos, principalmente conforme a complexidade do projeto aumenta. Durante o processo de desenvolvimento, é muito provável que o usuário queira acrescentar ou modificar algum requisito, sendo necessário uma reavaliação da especificação. Em vista deste problema podemos utilizar técnicas de Verificação de Modelos desenvolvidas para analisar uma especificação e verificar inconsistências, sendo que um processo automático diminuiria os custos e o tempo desprendido nesta operação. É exatamente com essa motivação que desenvolvemos nessa dissertação uma possível ferramenta para ajudar nessa atividade.

A teoria de Revisão de Crenças tem como objetivo manter a consistência de um conjunto de crenças (conjunto de informações) ao ser adicionada alguma nova informação. Podemos então utilizar tal teoria para manter consistente um modelo ao adicionarmos novas propriedades ou corrigirmos propriedades que deveriam ser válidas. Assim, a partir do modelo de uma especificação, descrito por uma linguagem formal, verificamos uma propriedade através do processo de Verificação de Modelos, e usando a teoria de Revisão de Crenças geramos sugestões para que o sistema continue consistente. É interessante que tal propriedade seja capaz de avaliar as interações do sistema ao longo de sua execução, isto é, através do tempo. Portanto usaremos Lógicas Temporais para definir nossas propriedades, pois elas são capazes de definir como determinadas propriedades se comportam ao longo da execução do programa. Diferentes métodos de Verificação de Modelos já foram propostos. O formato que escolhemos utiliza limitações no tamanho do caminho percorrido para poder verificar o modelo, sendo a verificação feita através de iterações na limitação do modelo e sugerindo mudanças a cada iteração.

\subsection{Objetivos}

O objetivo deste trabalho é utilizar o processo de Revisão de Crenças e Verificação de Modelos Limitada para avaliar especificações de um projeto utilizando propriedades descritas em Lógica Temporal, procurando inconsistências e revisá-las gerando sugestões na especificação, criando uma implementação para o processo descrito, disponibilizada em forma de software livre.

\subsection{Trabalho relacionados}

Um dos primeiros trabalhos com o qual tivemos contato foi a proposta de (de Sousa, 2007) na qual o autor implementou uma ferramenta para revisão de crenças em lógica CTL gerando sugestões 
de revisão par o modelo. O trabalho utiliza a técnica de verificação de modelos simbólica, descrita pelo trabalho de (Burch et al., 1990). Nosso trabalho segue uma proposta similar, porém com uma abordagem de verificação de modelos diferente.

Em (Finger e Wassermann, 2008) fomos apresentados ao conceito básico no qual fundamentamos nosso algoritmo de revisão e verificação. Finger e Wasserman sugeriram que utilizando um limite máximo para o tamanho dos caminhos e traduzindo tanto o modelo quanto a fórmula, é possível executar a revisão de crenças usando verificação de modelos limitada.

A abordagem de (Penczek et al., 2002) serviu como base para nosso algoritmo de tradução, os autores propuseram um algoritmo de tradução e verificação de modelos limitados e aplicaram-no para modeleos representados através de Elementary Net Systems. Nós aproveitamos o algoritmo proposto e o propomos uma implementação para uma Estrutura de Kripke.

O trabalho de (Zhang e Ding, 2008) foca no conceito de atualização de crenças através da verificação de modelos. Eles propõem o conceito de atualização admissível, onde temos a identificação das possíveis mudanças em uma estrutura de Kripke. Esse conceito é importante para nós, pois essas mudanças servirão como base para nosso framework de sugestões de mudança.

Por fim, o trabalho de (de Tarso Guerra Oliveira, 2016) traz uma análise sobre o estado de revisão de crença em lógicas temporais, discutindo sobre sua aplicação assim como a viabilidade de revisão de crenças e uma lógica temporal como CTL.

\subsection{Apresentação de um exemplo}

Durante toda a apresentação da proposta, iremos nos utilizar de um mesmo exemplo para apresentar cada seção do texto. Suponhamos que queremos especificar os estados de uma máquina de busca. Uma máquina de busca é um sistema que retorna pesquisas a partir de uma entrada. Ao levantar requisitos e avaliar quais estados são desejáveis podemos listar os seguintes estados:

- Espera: onde se aguarda a expressão de busca;

- Busca: onde são executados os algoritmos de busca;

- Cancelado: estado final, caso a busca seja interrompida;

- Resultado: estado final, caso a busca retorne um valor.

Além disso, quando a máquina de busca está em estado de espera ou buscando, dizemos que ela está ligada. Quando a máquina entra num estado final, dizemos que ela não está ligada. Tendo em vista tal exemplo, podemos verificar propriedades distintas como:

- Se a máquina de busca está pesquisando, futuramente entrará no estado de cancelamento ou no estado com resultados.

- O estado seguinte ao de espera é sempre o de busca.

- Após um estado final (cancelado ou com resultados), a máquina de busca retorna ao estado de espera.

- A máquina permanece ligada até alcançar um estado final.

- Existe a possibilidade de cancelar uma pesquisa.

- Não existe a possibilidade de a máquina ficar sempre ligada. 


\subsection{Organização do trabalho}

O trabalho será dividido da seguinte forma: No Capítulo ?? iremos apresentar os trabalhos relacionados à nossa proposta. No Capítulo 2 vamos definir os conceitos utilizados na teoria de revisão de crença usando Verificação de Modelos Limitada. Iremos descrever a estrutura usada para representar as especificações, a linguagem utilizada, o método de Verificação de Modelos e a teoria de Revisão de Crenças. No Capítulo 3 iremos apresentar e descrever o algoritmo proposto para resolver o problema de Revisão de Crenças. Nele apresentamos as duas principais contribuições originais do trabalho, a tradução de uma estrutura de Kripke para fórmula proposicional e a tradução reversa para a mesma. No Capítulo 4 iremos detalhar a implementação do algoritmo utilizado. No Capítulo 5 iremos apresentar os testes realizados, com seus resultados e uma análise do que obtivemos. Finalmente no Capítulo 6 apresentamos as conclusões e comentários finais sobre o trabalho. No Capítulo 6 itemos apresentas nossas conclusões finais e possíveis trabalhos futuros. 


\section{Capítulo 2}

\section{Conceitos básicos}

Neste capítulo iremos apresentar os principais conceitos necessários para a fundamentação do algoritmo de Revisão de Crenças utilizando Verificação de Modelos Limitada a ser proposto no Capítulo 3. Primeiramente na Seção 2.1 iremos apresentar a estrutura utilizada para representar os modelos a serem verificados; na Seção 2.2 iremos descrever a lógica utilizada para representar as propriedades a serem verificadas; na Seção 2.3 vamos apresentar os conceitos e tipos diferentes de Verificação de Modelos; e na Seção 2.4 vamos descrever a teoria de Revisão de Crenças.

\section{$2.1 \quad$ Estrutura de Kripke}

Definição 2.1. (Huth e Ryan, 2004) Uma Estrutura de Kripke é definida como uma quadrupla $(S, T, I, V)$, onde $\mathrm{S}$ é um conjunto de estados finito, $T \subseteq S \times S$ é o conjunto finito das transições, $I \subset S$ é o conjunto dos estados iniciais e $V: S \rightarrow 2^{P}$ é uma função que leva cada estado ao conjunto de proposições que são verdadeiras nele. A Figura 2.1 representa uma estrutura de Kripke onde: $P=\{a, b, c\}, S=\{s 0, s 1, s 2\}, T=\{(s 0, s 1),(s 0, s 2),(s 1, s 0),(s 1, s 2),(s 2, s 2)\}, I=\{s 0\}$ com $V(s 0)=\{a, b\}, V(s 1)=\{b, c\}$ e $V(s 2)=\{c\}$.

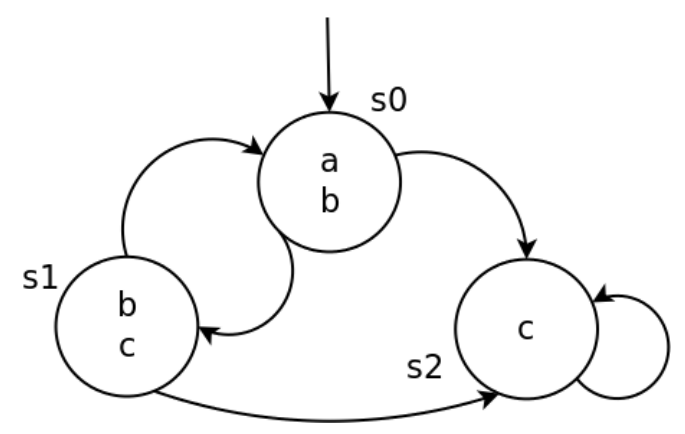

Figura 2.1: Estrutura de Kripke

Um caminho numa estrutura de Kripke é uma sequência de estados percorridos de acordo com as transições existentes entre os estados. Um caminho possível da estrutura representada pela Figura 2.1 é:

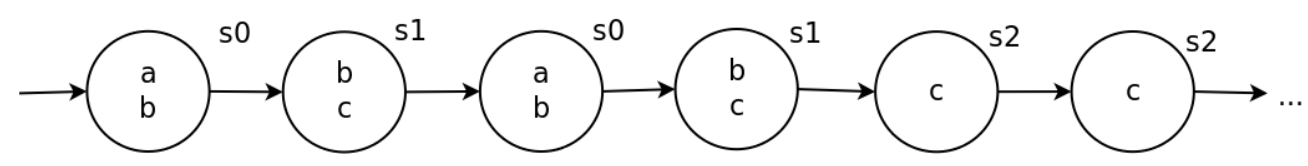

Figura 2.2: Um caminho da estrutura representada na Figura 2.1

Em relação ao exemplo apresentado na Seção 1.4, teríamos a estrutura de Kripke representada pela Figura 2.3 e com a seguinte assinatura: $K=(S, I, T, V)$, onde $S=\{s 0, s 1, s 2, s 3\}$ é o conjunto 
de estados, $I=\{s 0\}$ é o estado inicial, $T=\{(s 0, s 0),(s 0, s 1),(s 1, s 1),(s 1, s 2),(s 1, s 3)\}$ são as transições entre estados e $V$ é a função que leva um estado às proposições contidas no estado. Usaremos o seguinte conjunto de proposições: $P=\{$ ligado, espera,busca, resultado, cancelado $\}$, e a partir dele temos que $V(s 0)=\{$ espera,ligado $\}, V(s 1)=\{$ busca,ligado $\}, V(s 2)=\{$ resultado $\}, V(s 3)=$ $\{$ cancelado\}.

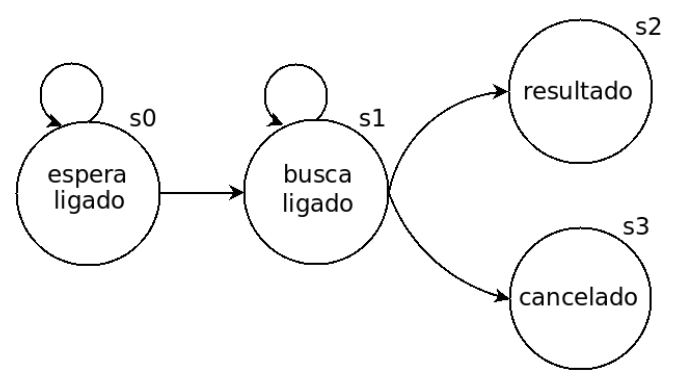

Figura 2.3: Máquina de busca

\subsection{Lógica temporal CTL}

Para representar a especificação de nossos sistema iremos utilizar lógica temporal. Lógicas temporais são um tipo de lógica onde se pode representar proposições relacionadas com sua ocorrência relativa no tempo. Por exemplo, podemos representar informações como: "Eu SEMPRE estou com fome"ou "Eu ficarei com fome ATÉ que eu coma". As duas principais lógicas temporais para a especificação de programas são a Linear Tree Logic (LTL) (Gabbay et al., 1980) e a Computation Tree Logic (CTL) (Clarke e Emerson, 1982); a primeira itera através dos caminhos, enquanto que a segunda utiliza ramificações. Apesar de podermos expressar propriedades em LTL que não são possíveis em CTL, o nosso contexto é melhor representado através de fórmulas em CTL e por isso a utilizaremos como nossa linguagem de representação.

\subsubsection{Sintaxe e Semântica}

A ideia por trás desta lógica é quantificar as possíveis execuções de um programa através da noção de caminhos que existem numa execução de um sistema. A sintaxe da CTL é dada pela seguinte definição no formato BNF (Huth e Ryan, 2004):

$$
\phi::=\perp|\top| p|\neg \phi| \phi \wedge \phi|(A X \phi)|(A G \phi)|(A F \phi)|(E X \phi)|(E G \phi)|(E F \phi)|E(\phi U \phi)| A(\phi U \phi)
$$

onde p é um símbolo proposicional atômico, $\neg$ e $\wedge$ são os operadores lógicos usuais e os demais são operadores de tempo. Cada operador temporal é composto por um quantificador de caminho ( $E$, "existe um caminho", ou $A$, "para todo caminho") seguido por um quantificador de estado $(X$, "próximo estado", $U$, "até", $G$, "sempre", ou $F$, "futuramente").

A Figura 2.4 exemplifica o significado de cada operador temporal: 


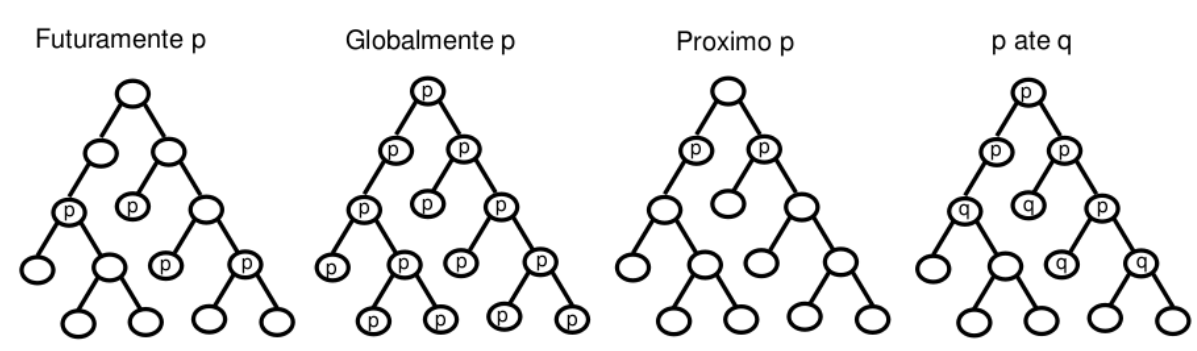

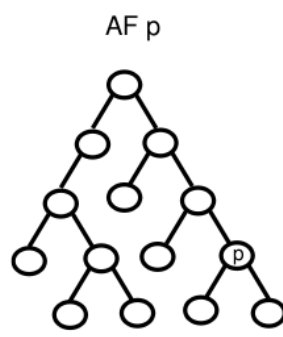

EF $p$
$A G p$

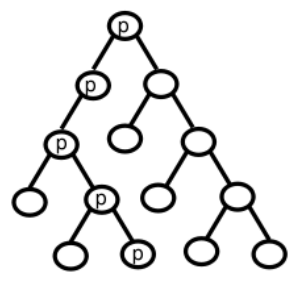

$E G p$

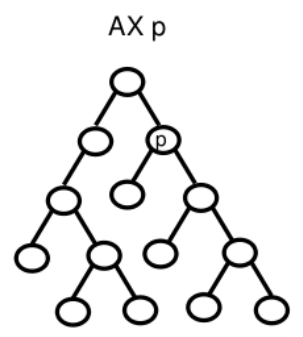

EXp
$A[p \cup q]$

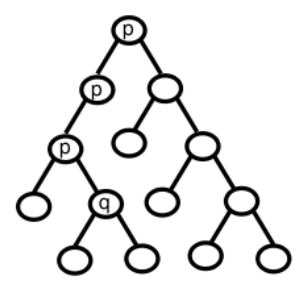

$E[p \cup q]$

Figura 2.4: Operadores temporais da CTL

Definição 2.2. (Huth e Ryan, 2004) Semântica CTL: Seja $M=(S, I, T, V)$ um modelo onde S é um conjunto de estados finito, $T \subseteq S \times S$ é o conjunto finito das transições, $I \subset S$ é o conjunto dos estados iniciais e $V: S \rightarrow 2^{P}$ é uma função que leva cada estado ao conjunto de proposições que são verdadeiras nele, e $\pi(i)$ o i-ésimo estado $s_{i}$ de um caminho, então dizemos que se $M, s \models \phi$, então $\phi$ é verdadeiro no estado $s$ de $M$. Assim temos:

1. $M, s \models p$ sse $p \in L(s)$

2. $M, s \models \neg \phi$ sse $M, s \not \models \phi$

3. $M, s \models \phi_{1} \wedge \phi_{2}$ sse $M, s \models \phi_{1}$ e $M, s \models \phi_{2}$

4. $M, s \models E X \phi$ sse existe um estado $s^{\prime}$ de $M$ tal que $\left(s, s^{\prime}\right) \in T$ e $M, s^{\prime}=\phi$

5. $M, s \models E G \phi$ sse existe um caminho $\pi$ de $M$ tal que $\pi(1)=s$ e $\forall i \geqslant 1, M, \pi(i) \models \phi$

6. $M, s \models E\left(\phi_{1} U \phi_{2}\right)$ sse existe um caminho $\pi$ de $M$ tal que $\pi(1)=s$ e $\exists i \geqslant 1$,

$M, \pi(i) \models \phi_{2} e \forall j, i>j \geqslant 1, M, \pi(j) \models \phi_{1}$

Ao trabalharmos com CTL iremos apenas utilizar a combinação de quantificadores EX, EG e $\mathrm{E}(\phi \mathrm{U} \phi)$, a fim de simplificarmos os algoritmos de verificação. Os demais operadores podem ser derivados através das fórmulas (Finger e Wassermann, 2008):

$$
\begin{gathered}
A X \phi=\neg E X \neg \phi \\
A G \phi=\neg E F \neg \phi \\
A F \phi=\neg E G \neg \phi \\
E F \phi=E[\top U \phi] \\
A[\phi U \beta]=\neg(E[\neg \beta U(\neg \phi \wedge \neg \beta)] \vee E G \neg \beta)
\end{gathered}
$$

Além disso, $\alpha \rightarrow \beta$ é definido como $\neg \alpha \vee \beta$.

A lógica $E C T L$ é o fragmento existencial da lógica CTL tal que a negação só pode ser aplicada aos símbolos proposicionais e somente temos operadores de caminho do tipo E. A lógica $A C T L$ é o fragmento universal da lógica CTL tal que sua linguagem é definida como $\{\neg \psi \mid \psi \in E C T L\}$. 
Podemos ver que $A C T L$ consiste de fórmulas temporais da forma: $A X \phi, A(\phi U \phi)$ e $A F \alpha$. Em (Grumberg e Long, 1994; Penczek et al., 2000, 2002) é mostrado que ACTL é uma lógica com uma expressividade satisfatória e portanto, neste trabalho, utilizaremos apenas fórmulas em ACTL de acordo com o trabalho proposto em (Penczek et al., 2002).

\subsubsection{Tipos de Propriedades}

O trabalho de (Lamport, 1977) introduz dois tipos principais de propriedades identificadas no processo de verificação formal: propriedades liveness e safety.

\section{Liveness}

Uma propriedade do tipo liveness garante que algo bom eventualmente acontece. Um exemplo de propriedade desse tipo é a de starvation freedom que garante que todos os processos que desejam acessar uma região crítica eventualmente fazem progresso. Podemos observar que propriedades deste tipo podem ser representadas em ECTL.

\section{Safety}

Uma propriedade do tipo safety garante que nada ruim acontece. Um exemplo de propriedade desse tipo é a de mutual exclusion que garante que dois processos não estão na região crítica ao mesmo tempo. Diferentemente das propriedades do tipo liveness as propriedades do tipo safety procuram garantir um estado consistente por toda a aplicação, logo, podemos observar que propriedades deste tipo podem ser representadas em $A C T L$

Alguns autores, como (Bérard et al., 2001), afirmam que para razões práticas de verificação formal, as únicas propriedades úteis são as do tipo safety. Ele argumenta que uma propriedade do tipo liveness apenas garante que um evento irá ocorrer sem dar uma sugestão da demora envolvida. Pode ser que para provar uma propriedade liveness seja necessário um tempo arbitrário extremamente longo. Isso torna, de um ponto de vista prático, essa propriedade desnecessária, já que normalmente não temos como esperar todo o tempo necessário para a sua verificação. Além disso, se limitarmos a quantidade de tempo necessário para alcançar uma propriedade do tipo liveness, tornamos ela uma propriedade do tipo safety.

Portanto, iremos verificar apenas propriedades do tipo safety que podem ser expressadas em $A C T L$. Isso tornará nossa solução mais simples, pois para verificar uma propriedade do tipo safety, basta encontrarmos um contra-exemplo onde essa propriedade não é válida. Essa restrição também vai de encontro com a solução do problema de indecidibilidade exposto na Seção 2.4.5 e discutido posteriormente na Seção 3.4.

\subsubsection{Exemplos}

Podemos transcrever as propriedades desejáveis do nosso exemplo de uma máquina de busca para a lógica CTL:

1. Sempre que a máquina de busca está pesquisando, futuramente entrará no estado de cancelamento ou no estado com resultados.

$A G($ busca $\rightarrow A F($ cancelado $\vee$ resultado $))$

2. Sempre, o estado seguinte ao de espera é o de busca.

$A G($ espera $\rightarrow A X($ busca $))$

3. Sempre, um estado final (cancelado ou com resultados) implica que o próximo estado da máquina de buscas é o estado de espera.

$A G(($ cancelado $\vee$ resultado $) \rightarrow A X($ espera $))$

4. Sempre, a máquina permanece ligada até alcançar um estado final.

$A G($ A (ligada $U$ (cancelado $\vee$ resultado $))$ 
5. Sempre existe a possibilidade de cancelar uma pesquisa. $A G($ busca $\rightarrow E X($ cancelado $))$

6. Não existe a possibilidade de a máquina ficar sempre ligada. $\neg E G(A G($ ligada $))=A G(E G(\neg l$ igada $))$

Os itens 5 e 6 não podem ser descritos utilizando ACTL e portanto não serão analisados nesta abordagem. Essa é uma limitação do algoritmo base de verificação proposto por (Penczek et al., 2002) e também decorre dos resultados de indecidibilidade que serão discutidos posteriormente nas Seções 2.4.5 e 3.4 .

\subsection{Verificação de modelos}

A Verificação de Modelos (Clarke et al., 1999; Huth e Ryan, 2004) é uma das técnicas mais conhecidas de verificação de sistemas (que podem ser modelados como uma máquina de estados finitos) e vem sendo desenvolvida desde a década de 80. Basicamente consiste em: dada uma propriedade em alguma lógica temporal, verificar se a máquina de estados finitos que representa o sistema satisfaz aquela fórmula. Ou seja, verificar se uma fórmula $f$ é satisfeita por um grafo $G$ de estados, rotulados com as proposições que são válidas naquele estado.

Iremos utilizar a representação por meio de estruturas de Kripke, no entanto, ela sofre de um problema chamado Problema de Explosão de Estados (Burch et al., 1990). Isto é, conforme a complexidade do sistema aumenta, o número de estados cresce exponencialmente tornando inviável a verificação da estrutura devido ao armazenamento de estados.

Diferentes abordagens foram desenvolvidas para tentar solucionar o problema da explosão de estados. As mais conhecidas são: Verificação de Modelos Simbólica (Burch et al., 1990) e Verificação de Modelos Limitada (Biere et al., 1999), que iremos descrever brevemente a seguir. Em nosso sistema, iremos utilizar a abordagem de Verificação de Modelos Limitada, a qual a partir de agora nos referiremos como $B M C$ derivado do inglês bounded model checking.

\subsubsection{Verificação de modelos simbólica}

A ideia básica por trás da verificação de modelos simbólica é compactar grandes estruturas de Kripke através de diagramas de decisão binários (binary decision diagrams) ou BDDs (Burch et al., 1990). Um BDD é um grafo acíclico dirigido com vértices não terminais, arcos anotados de 0 e 1 e dois vértices terminais que permite representar e manipular funções booleanas. Os vértices não terminais possuem variáveis binárias e os arcos que saem desses vértices são rotulados com 0 ou 1. Um vértice terminal é rotulado com 0 ou com 1 , representando os valores booleanos falso e verdadeiro.

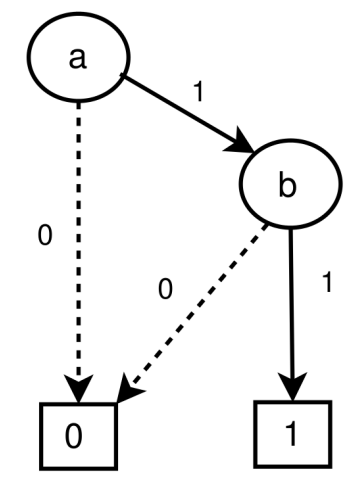

Figura 2.5: $B D D$ de $\alpha \wedge \beta$

Assim, uma estrutura de Kripke é traduzida em expressões booleanas e representadas através de BDDs aumentando o número de estados armazenáveis computacionalmente dessa estrutura. Esta é 
a abordagem utilizada por (de Sousa, 2007) para implementar seu algoritmo de revisão de crenças em CTL.

\subsubsection{Verificação de modelos limitada}

A solução proposta pela verificação de modelos limitada, ou bounded model checking (BMC), (Biere et al., 1999) é de colocar um limite $k$ no tamanho máximo dos caminhos e então aplicar um programa eficiente na solução de problemas intratáveis, como um resolvedor SAT. Desta forma resolvemos um outro problema, simplificado, que é o de que o modelo com um caminho de tamanho no máximo $k$ satisfaz o conjunto de propriedades verificadas. A partir desse limite é possível traduzir a estrutura de Kripke e uma fórmula em ECTL para fórmulas proposicionais, verificando sua satisfazibilidade num resolvedor SAT. Ou seja, verificamos se existe um caminho no modelo que satisfaz a fórmula em ECTL.

Para podermos executar a tradução precisamos de uma nova semântica para a CTL, que chamaremos Semântica CTL k-limitada (Finger e Wassermann, 2008).

Definição 2.3. (Penczek et al., 2002) k-caminho: Seja $M=(S, I, T, L)$ um modelo, um $k$-caminho é sequencia finita de estados $\pi=\left(s_{0}, \ldots, s_{k}\right)$ tal que $\left(s_{i}, s_{i+1}\right) \in T$ para cada $0<i<k$.

Definição 2.4. (Finger e Wassermann, 2008; Penczek et al., 2002) k-loop: Um $k$-loop é um $k-$ caminho $\pi$ que possui um loop, isto é, $(\pi(i), \pi(j)) \in T$ tal que $0 \leq i<j \leq k$

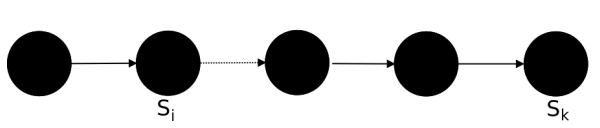

Sem loop

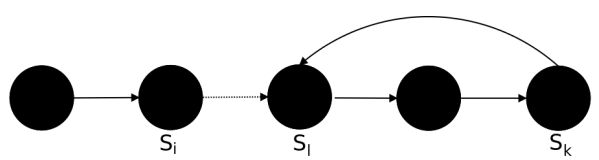

$(k, l)$ loop

Figura 2.6: $k$-loop

Definição 2.5. (Finger e Wassermann, 2008) A semântica CTL $k$-limitada, $M, s \models{ }^{k} \phi \operatorname{com} k \geqslant 0$, é definida por:

1. $M, s \mid{ }^{k}$ p sse $p \in L(s)$

2. $M, s \models{ }^{k} \neg \phi$ sse $M, s \not \not^{k} \phi$

3. $M, s \models{ }^{k} \phi_{1} \wedge \phi_{2}$ sse $M, s \models{ }^{k} \phi_{1}$ e $M, s \models{ }^{k} \phi_{2}$

4. $M, s \models{ }^{k} E X \phi$ sse existe um estado $s^{\prime}$ de $M$ tal que $\left(s, s^{\prime}\right) \in T$ e $M, s^{\prime} \models^{k-1} \phi$

5. $M, s \models{ }^{k}$ EG $\phi$ sse existe um $k-$ loop $\pi$ de $M$ tal que $\pi(1)=s$ e $\forall i \geqslant 1, M, \phi(i) \mid={ }^{k-i} \phi$

6. $M, s \models{ }^{k} E\left(\phi_{1} U \phi_{2}\right)$ sse existe um caminho $\pi$ de $M$

tal que $\pi(1)=s$ e $\exists i \geq 1$,

$M, \pi(i) \models{ }^{k-i} \phi_{2} \wedge \forall j, i>j \geqslant 1, M, \pi(j) \models{ }^{k-j} \phi_{1}$

Para executar a verificação usamos o limite $k$ para traduzir uma estrutura de Kripke $K$ em uma fórmula proposicional $K^{k}$ e uma fórmula em CTL $\phi$ numa fórmula proposicional $A_{\phi}^{k}$. Em seguida submetemos uma fórmula $K^{k} \wedge A_{\phi}^{k}$ no resolvedor SAT para obter um veredito. Se a fórmula é insatisfazível, isso significa que $\neg \phi$ vale na estrutura de Kripke $K$ até o limite estabelecido. Caso contrário uma valoração $v$ é retornada pelo resolvedor SAT, a qual representa um caminho através do modelo no qual $\phi$, uma fórmula em ECTL, vale. 


\subsection{Revisão de crenças}

A Revisão de Crenças teve como fundamento a necessidade de modelar o comportamento de bases de conhecimento que ao receberem novas informações se tornam inconsistentes. Assim, o objetivo principal da Revisão de Crenças é manter o conjunto de crenças sempre consistente. As bases da teoria de Revisão de Crenças foram desenvolvidas por Alchourrón, Gärdenfors e Makinson (Alchourrón et al., 1985; Gärdenfors, 1988), no início da década de 80, onde propuseram postulados que descrevem as propriedades formais que um processo de revisão deve obedecer. O trabalho é normalmente conhecido como paradigmas $A G M$, devido as iniciais dos autores. Um dos principais fundamentos da teoria de Revisão de Crenças, é o Princípio da Mudança Mínima, ou PMM, que determina que a mudança no conjunto original de crenças seja a mínima possível, ou seja, que a mudança deve reter o máximo de informações possíveis.

\subsubsection{Operadores}

Existem três tipos de operações (Gärdenfors, 1988), e cada uma delas possui seus postulados a fim de que o Princípio da Mudança Mínima seja satisfeito quando uma mudança é realizada. Seja $K$ um conjunto de crenças e $\alpha$ uma nova informação (crença), temos:

1. Expansão $(\boldsymbol{K}+\alpha)$ : Uma informação (crença) consistente $\alpha$ é adicionada ao conjunto, juntamente com as consequências lógicas de $K \cup \alpha$.

2. Contração $(K-\alpha)$ : A informação (crença) $\alpha$ é abandonada. Como o conjunto $K$ é logicamente fechado, é possível que seja necessário abandonar outras crenças que impliquem em $\alpha$.

3. Revisão $(\boldsymbol{K} * \alpha)$ : Uma informação (crença) $\alpha$ é acrescentada ao conjunto $K$ e para manter a consistência pode ser necessário abandonar outras crenças de $K$.

Descreveremos a seguir: a linguagem que usaremos para representar cada crença; algumas representações possíveis para um conjunto de crenças; os principais postulados que fundamentam a teoria de Revisão de Crenças; e duas relações importantes entre revisão e contração.

\subsubsection{Representação}

Primeiramente precisamos saber como representar cada estado epistêmico (de conhecimento, crença ou informação), neste trabalho utilizamos uma representação proposicional. Desta forma, iremos utilizar a linguagem $L$, que compreende a linguagem proposicional e seus conectivos lógicos. Usaremos a notação $K \vdash \alpha$, se $K$ implica logicamente $\alpha, K \nvdash \alpha$, se $K$ não implica logicamente $\alpha$, e $C n(K)$ para o conjunto de todas as consequências lógicas de $K$.

Em seguida veremos algumas das representações mais comuns utilizadas para representar estados epistêmicos (Gärdenfors, 1988):

- Conjunto de Crenças: É um conjunto de fórmulas logicamente fechado, ou seja, se $K \vdash \alpha$, sendo $K$ um conjunto, então $\alpha \in K$. Ao utilizar tal representação, estamos propensos a trabalhar com conjuntos infinitos, o que não é apropriado do ponto de vista computacional.

- Base de Crenças: Supõe que um conjunto de crenças possui uma base para inferir todas as crenças de um conjunto. $B_{k}$ é uma base para um conjunto de crenças $K$ se e somente se $B_{k}$ é um subconjunto finito de $K$ e o fecho lógico de $B_{k}$ é igual ao conjunto $K$. Logicamente podemos ter várias bases para um mesmo conjunto $K$. Do ponto de vista computacional, por trabalhar com conjuntos finitos, essa representação tem sido bastante utilizada. É a representação utilizada por (Finger e Wassermann, 2008) e a qual seguiremos também.

- Mundos Possíveis: Baseia-se na ideia de um conjunto $W_{k}$ de mundos possíveis. Qualquer conjunto de crenças $K$ pode ser representado pelo subconjunto $W_{k}$ dos mundos possíveis em 
que todas as sentenças de $K$ são verdadeiras. Essa representação é muito utilizada por lógicos e filósofos e começa a ser usada computacionalmente.

\subsubsection{Postulados}

Vamos assumir que estamos utilizando a representação dos estados epistêmicos como conjunto de crenças. A motivação por trás dos postulados é que o Princípio da Mudança Mínima seja satisfeito a cada operação (Gärdenfors, 1988).

\section{Expansão}

Dado um conjunto de crenças $K$ e uma crença $\alpha$, definimos a expansão como:

$$
K+\alpha=C n(K \cup \alpha)
$$

não sendo necessário a definição de postulados.

\section{Revisão}

Dado um conjunto de crenças $K$ e uma crença $\alpha$, os seis postulados básicos da revisão (mais dois extras) são:

1. $K * \alpha$ é um conjunto de crenças;

2. $\alpha \in K * \alpha$;

3. $K * \alpha \subseteq K+\alpha$;

4. Se $\neg \alpha \notin K$, então $K+\alpha \subseteq K * \alpha$;

5. $K * \alpha$ é inconsistente sse $\vdash \neg \alpha$;

6. Se $\alpha \leftrightarrow \beta$, então $K * \alpha=K * \beta$;

O postulado 1 garante que o resultado de uma revisão continua sendo um conjunto de crenças. $\mathrm{O}$ postulado 2 afirma que a crença recebida deve pertencer ao conjunto de crenças revisado, garantindo assim o sucesso da revisão. O postulado 3 garante que nenhuma outra informação é adicionada ao conjunto de crenças. O postulado 4 afirma que se a nova informação adicionada for consistente, a expansão está contida na revisão. Em união ao postulado 3 , temos que a expansão é igual à revisão. O postulado 5 afirma que o resultado da revisão só é inconsistente somente se a fórmula usada para a revisão for inconsistente. O postulado 6 garante que a revisão feita por crenças equivalentes resulta em conjuntos revisados equivalentes.

Há ainda dois postulados extras para revisões por conjunções:

7. $K *(\alpha \wedge \beta) \subseteq(K * \alpha)+\beta$;

8. Se $\neg \beta \notin K * \alpha$, então $(K * \alpha)+\beta \subseteq K *(\alpha \wedge \beta)$.

Os postulados $\mathbf{7}$ e $\mathbf{8}$ juntos afirmam que se uma das fórmulas for consistente com o conjunto revisado pela outra, o conjunto revisado pela conjunção dessas crenças é igual ao conjunto resultante da revisão de uma das fórmulas pela expansão da outra. 


\section{Contração}

Dado um conjunto de crenças $K$ e uma crença $\alpha$, os seis postulados básicos da contração (mais dois extras) são:

1. $K-\alpha$ é um conjunto de crenças;

2. $K-\alpha \in K$

3. Se $\alpha \notin K$, então $K-\alpha=K$;

4. $\nvdash \alpha$, então $\alpha \notin K-\alpha$;

5. $K \subseteq(K-\alpha)+\alpha$;

6. Se $\vdash \alpha \leftrightarrow \beta$, então $K-\alpha=K-\beta$;

O postulado 1 afirma que o resultado da contração de um conjunto de crenças é ainda um conjunto de crenças. O postulado $\mathbf{2}$ garante que nenhuma nova fórmula é adicionada em uma operação de contração. O postulado 3 afirma que se a crença não pertencer ao conjunto, o conjunto permanece inalterado. O postulado 4 afirma que a sentença contraída não fará parte do conjunto resultante, garantindo o sucesso da contração. O postulado 5 afirma que o conjunto de crenças original pode ser recuperado através da expansão pela crença contraída. O postulado 6 garante que duas crenças equivalentes, quando contraídas em um mesmo conjunto de crenças, resultam em conjuntos equivalentes.

Há ainda dois postulados extras para contrações por conjunções:

7. $K-\alpha \cap k-\beta \subseteq K-(\alpha \wedge \beta)$;

8. Se $\alpha \notin K-(\alpha \wedge \beta)$, então $K-(\alpha \wedge \beta) \subseteq K-\alpha$.

Os postulados $\mathbf{7}$ e $\mathbf{8}$ juntos afirmam que se uma das fórmulas não pertencer à contração do conjunto pela intersecção das crenças, a contração feita pela conjunção das fórmulas é igual à conjunção dos conjuntos contraídos pelas fórmulas separadamente.

\subsubsection{Revisão versus Contração}

Existem duas relações importante entre os operadores de revisão e contração, conhecidas como:

- Identidade de Harper: $K-\alpha=K \cap(K * \neg \alpha)$

- Identidade de Levi: $K * \alpha=(K-\neg \alpha)+\alpha$

Estas identidades mostram como podemos relacionar um operador ao outro. Para nós a identidade de Levi é a mais importante, pois ela nos mostra que para efetuarmos uma revisão, podemos executar uma contração seguida de uma expansão. Portanto, se tivermos um mecanismo eficaz de contração podemos efetuar a revisão de uma base de crenças. Este é o caminho que seguiremos para efetuar uma Revisão de Crenças.

\subsubsection{Indecidibilidade de uma contração em lógicas temporais}

Em (de Tarso Guerra Oliveira, 2016) foi mostrado que para a lógica LTL, e outras lógicas temporais como CTL, encontrar um operador de partial meet contraction não é factível, isto é indecidível. No entanto, eles mostraram que é possível encontrar uma contração se utilizarmos métodos de aproximação e limitação dos elementos utilizados na contração. Esse é o caminho proposto por (Finger e Wassermann, 2008) e que utilizaremos para propor uma revisão à nossa especificação. Através de uma limitação no tamanho máximo do caminho percorrido no modelo, podemos aproximar o modelo, e iterando no tamanho do caminho, encontrar uma revisão para a especificação.

A relação do algoritmo proposto e do problema de indecidibilidade será discutido na Seção 3.4 após descrevermos melhor a solução proposta a seguir. 


\section{Capítulo 3}

\section{Revisão de crenças temporais com verificação de modelos limitada}

Até aqui, discorremos sobre o processo de Revisão de Crenças temporais, suas características e postulados. Vimos também uma forma de modelar os estados epistêmicos através de uma lógica temporal conhecida como CTL. E por fim analisamos o processo de Verificação de Modelos, a fim de encontrarmos um modo de verificar o conjunto de crenças atrás de inconsistências e apontálas. Seguiremos então a seguinte ideia, proposta em (Finger e Wassermann, 2008), para tratar o problema de verificar especificações e sugerir correções, representado pela Figura 3.1.

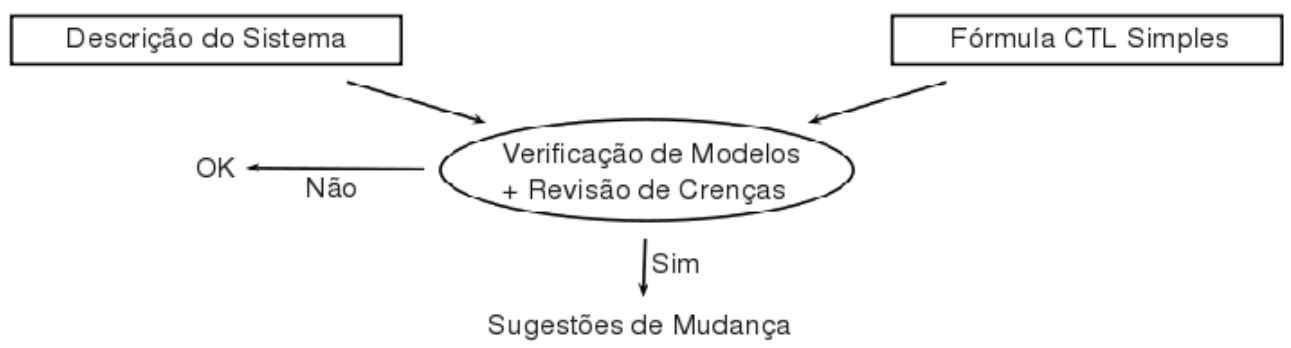

Figura 3.1: Verificação de modelos com revisão de crenças

Em (Flouris, 2006) foi mostrado que os postulados AGM podem ser aplicados somente para lógicas que são decomponíveis, isto é, uma lógica $\langle L, C n\rangle$, onde $L$ é o conjunto de fórmulas e $C n$ é o operador de consequência, é decomponivel se para todo conjunto de fórmulas em $L(A, B \subseteq L)$ se $C n(\emptyset) \subset C n(B) \subset C n(A)$, existe um terceiro conjunto $C(C \subseteq L)$ tal que $C n(C) \subset C n(A)$ e $C n(B \cup C)=C n(A)$. CTL (e lógicas modais em geral) são decomponíveis. Isso significa que as operações de revisão podem ser aplicadas. No entanto, o uso de conjuntos logicamente fechados leva a problemas do ponto de vista computacional, já que são tipicamente infinitos.

Para bases de crenças, (Wassermann e Hansson, 1998) mostrou que se uma lógica é compacta e monotônica, as construções típicas podem ser aplicadas. Mas CTL e outras lógicas baseadas em tempo discreto não são compactas. No entanto, o trabalho descrito em (Finger e Wassermann, 2008) mostra que é possível revisar modelos em tais lógicas. Para tal é necessário utilizarmos Verificação de Modelos Limitada e traduzirmos para lógica proposicional, tanto a especificação quando as fórmulas CTL, de forma que possamos aplicar um resolvedor SAT. A partir desta estratégia, temos que a existência de um modelo revisado é garantido na lógica proposicional. Desta forma, a partir desta estratégia, propomos um framework para traduzir o modelo e as propriedades para a lógica proposicional, efetuar a Verificação de Modelos Limitada, gerar as sugestões de mudança a partir de heurísticas e traduzir a revisão para a linguagem utilizada na especificação.

Ao utilizarmos o método de Verificação de Modelos Limitada não estamos verificando o modelo como um todo, apenas um fragmento do modelo com caminhos até um tamanho especificado $k$. Isso faz com que após o término da verificação seja necessário executar um outro verificador ilimitado 
para validar se não existem caminhos maiores que $k$ e que ainda não satisfazem a propriedade desejada. De acordo com (de Tarso Guerra Oliveira, 2016) não é factível encontrar um operador de partial meet contraction para o caso genérico, logo essa limitação é necessária para revisarmos o modelo. Na Seção 3.1.4 descrevemos como esse processo será feito e discutiremos o tamanho máximo de $k$ necessário para validar completamente o modelo.

\subsection{Algoritmo}

Nosso trabalho segue a linha proposta em (Finger e Wassermann, 2008). Iremos utilizar ACTL para representar nossas crenças e usar o método de Bounded Model Checking (BMC) a fim de encontrarmos inconsistências e corrigi-las, até conseguir um conjunto consistente, retornando sugestões de alterações para o usuário. A ideia do algoritmo é receber uma especificação em ACTL, transcrevê-la para a lógica proposicional clássica e por fim aplicar o processo de revisão por BMC, gerando as sugestões de mudanças, como representado na 3.2. Iremos focar apenas na parte interna do algoritmo onde será utilizado a Verificação de Modelos Limitada.

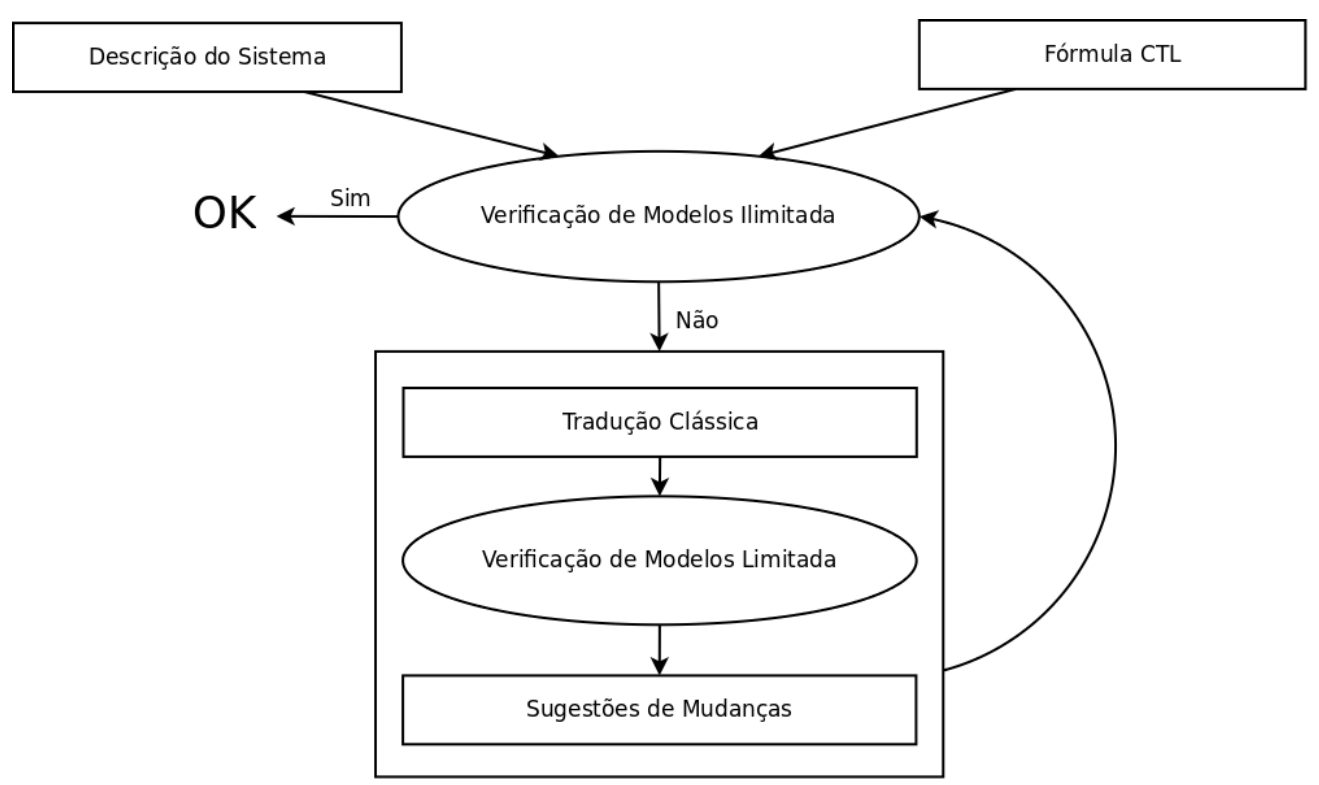

Figura 3.2: Revisão de crenças com verificação de modelos limitada (Finger e Wassermann, 2008)

Iremos receber como entrada do algoritmo: nosso modelo representado por uma estrutura de Kripke, uma fórmula ACTL (fragmento universal da CTL) e o limite inicial a ser usado. Podemos começar com um limite inicial $k$ baixo ou podemos usar um outro verificador para encontrarmos um caminho falho e partir deste tamanho de caminho. Discutiremos a escolha do limite $k$ e o limite máximo necessário para verificação na Seção 3.2.

O objetivo da verificação é encontrar contra exemplos que indiquem que a fórmula ACTL $\psi$ não é válida, por isso iremos utilizar a negação da fórmula CTL durante o processo. Dessa forma, com o limite fixo $k$, traduzimos a estrutura de Kripke $M$ e a negação da fórmula ACTL $\varphi=\neg \psi$ para lógica clássica utilizando um limite $k$, gerando as fórmulas proposicionais $M^{k}$ e $A_{\varphi}^{k}$ respectivamente. Em seguida submetemos a fórmula $M^{k} \wedge A_{\varphi}^{k}$ a um resolvedor SAT. A partir da resposta geramos as sugestões de mudança no modelo e criamos uma fórmula proposicional $M_{\text {rev }}$ representando o modelo revisado para um limite $k$.

Após a revisão, traduzimos $M_{\text {rev }}$, uma fórmula proposicional clássica, de volta em sugestões de alteração na especificação original $M$. Para executar a tarefa de tradução, temos que comparar a tradução inicial $M^{k}$ com a teoria revisada $M_{\text {rev }}$ e trazer as diferenças de volta para a especificação. Feita a comparação, basta interpretar a especificação revisada. Pode ser que após as correções o modelo ainda não esteja completamente revisado, para isso devemos incrementar o valor de $k$ e 
reexecutar o processo.

Desta forma o algoritmo pode ser resumido nos passos a seguir, representado na Figura 3.3:

1. Tradução inicial: A tradução do modelo e da fórmula para lógica proposicional;

2. Verificação e Revisão: Verificação da fórmula traduzida e revisão da fórmula;

3. Tradução reversa: A tradução do modelo com as sugestões de volta para a linguagem original;

4. Verificação final e iteração em $k$ : Verificação se o modelo satisfaz a fórmula original e incremento de $\mathrm{k}$ em caso negativo.

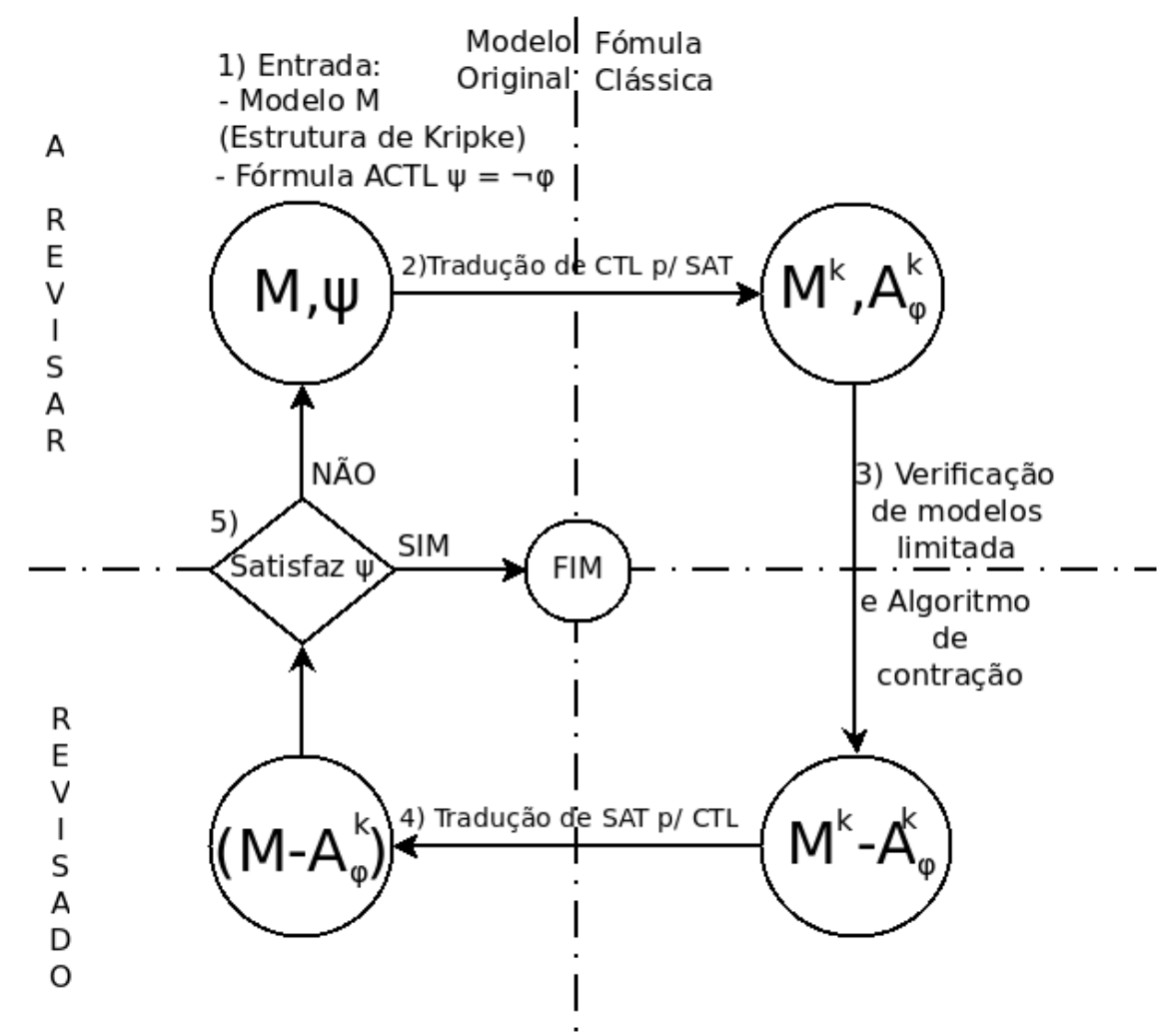

Figura 3.3: Representação do algoritmo de revisão de crenças com $B M C$

Esses passos serão descritos mais detalhadamente a seguir.

\subsubsection{Tradução inicial}

A tradução para lógica proposicional é uma implementação do algoritmo proposto por (Penczek et al., 2002) para uma estrutura de Kripke. Foi utilizada uma implementação para ECTL, um fragmento da CTL, onde a negação só pode ser aplicada a proposições, seguindo a semântica CTL k-limitada demonstrada anteriormente. Como queremos revisar em relação a fórmulas em ACTL, que pode ser definida como $\{\neg \varphi \mid \varphi \in E C T L\}$, iremos verificar sua negação, ou seja, uma fórmula em ECTL. Além disso, utilizaremos um resolvedor SAT para verificar a satisfazibilidade da fórmula, portanto para facilitar os aspectos computacionais precisamos gerar nossas fórmulas na Forma Normal Clausal (Clausal Normal Form ou CNF), formada por conjunções de disjunções.

Definição 3.1. Seja $M=(S, T, I, V)$ um modelo representado por uma estrutura de Kripke, onde $S$ é o conjunto de estados, $T$ é o conjunto das transições, $I$ é o único estado inicial e $V$ uma função que relacionado os estados aos valores das variáveis proposicionais, e seja $k \in \mathbb{N}^{+}$. Na Seção 2.1 definimos nosso modelo com um conjunto de estados iniciais. Para nosso algoritmo iremos considerar modelos com apenas um estado inicial. 
Definição 3.2. (Penczek et al., 2002) O $k$-modelo para $M$ é uma estrutura $M_{k}=\left(S\right.$, Caminho $\left._{k}, I, V\right)$ onde Caminho $_{k}$ é um conjunto de todos os $k$ - caminhos de $M$.

Definição 3.3. (Penczek et al., 2002) Para um subconjunto Caminho' $\subseteq$ Caminho $_{k}$ definimos Estados $\left(\right.$ Caminho $\left.^{\prime}\right)=s \in S \mid() \exists \pi \in$ Caminho $\left.^{\prime}\right)(\exists i \leq k) \pi(i)=s$

Definição 3.4. (Penczek et al., 2002) Dizemos que uma estrutura $M_{k}^{\prime}=\left(\left(S^{\prime}, C a m i n h o_{k}^{\prime}, I\right), V^{\prime}\right)$ é

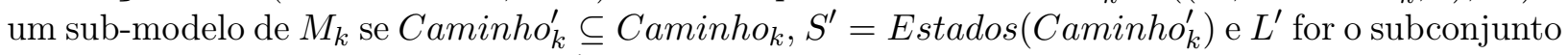
das proposições de $L$ contidas em $S^{\prime}$.

Representamos cada estado de $S$ como um vetor de variáveis proposicionais $s=(s[1], \ldots, s[n])$ onde $s[i]$ é uma variável proposicional e $n=\left\lceil\log _{2}(|S|)\right\rceil$. E de forma crescente, atribuimos uma valoração binária para cada estado. Desta forma se tivermos três estados, $S=\left\{s_{0}, s_{1}, s_{2}\right\}$ teremos as seguintes valorações: $s_{0}=(0,0), s_{1}=(0,1)$ e $s_{2}=(1,0)$.

Precisaremos da função $f_{k}$, que determina o número de $k$ - caminhos de um submodelo $M_{k}^{\prime}$ suficientes para checar uma fórmula em ECTL, definida em (Penczek et al., 2002) e listada abaixo:

- $f_{k}(p)=f_{k}(\neg p)=0$, onde $p \in \mathcal{P V}$ e $\mathcal{P V}$ é o conjunto de variáveis proposicionais;

- $f_{k}(\alpha \vee \beta)=\max \left\{f_{k}(\alpha), f_{k}(\beta)\right\}$;

- $f_{k}(\alpha \wedge \beta)=f_{k}(\alpha)+f_{k}(\beta)$;

- $f_{k}(E X \alpha)=f_{k}(\alpha)+1$

- $f_{k}(E G \alpha)=(k+1) * f_{k}(\alpha)+1$;

- $f_{k}(E(\alpha U \beta))=k * f_{k}(\alpha)+f_{k}(\beta)+1$.

Utilizaremos a função $f_{k}$ para definir o número de caminhos que devem ser verificados. Para montarmos as fórmulas da tradução do modelo e da fórmula ACTL, iremos utilizar as seguintes fórmulas proposicionais (Penczek et al., 2002):

- $\operatorname{lit}(v, p)$, onde $v=\{0,1\}$, que define se uma variável $p$ é positiva ou negativa.

- $I_{s}(w)$ é verdadeira se e somente se a valoração de $w$ codifica o estado $s$.

- $T(w, v)$ é verdadeiro se e somente se existe uma transição de $w$ a $v$.

- $V(w, p)$ é verdadeiro se e somente se variável $p$ for verdadeira em $w$.

- $H(w, v)$ é verdadeiro se e somente se $w=v$.

Para verificarmos nosso modelo dentro da lógica clássica iremos utilizar um resolvedor SAT. Em nossa implementação, iremos utilizar o $z$ Chaff (https://www.princeton.edu/c̃haff/zchaff.html) que recebe como entrada uma fórmula proposicional na forma normal conjuntiva ou CNF (Conjunctive Normal Form) (Huth e Ryan, 2004). Portanto nossas fórmulas serão todas definidas em CNF. Para isso, precisaremos de uma fórmula normalizadora que defina uma variável proposicional para uma fórmula qualquer. Assim, seja $\alpha=v_{1} \wedge \ldots \wedge v_{m}$, onde $v_{1}, \ldots, v_{m}$ são disjunções, usaremos a função $D$, que define a variável $a$ para a fórmula $\alpha$, isto é, $a \Longleftrightarrow \alpha$, da seguinte forma:

$$
D(a, \alpha):=\bigwedge_{i=1}^{m}\left(\neg a \vee v_{i}\right) \wedge \bigwedge_{i=1}^{m} \bigwedge_{j=1}^{n}\left(a \vee \neg v_{i_{j}}\right)
$$

onde $v_{i_{1}}, \ldots, v_{i_{n}}$ são as proposições de $v_{i}$.

Definimos então as fórmulas proposicionais descritas acima como:

- $\operatorname{lit}(0, p)=\neg p$ e $\operatorname{lit}(1, p)=p$, onde $p \in \mathcal{P} \mathcal{V}$ 
- $I_{s}\left(s_{i, j}\right):=\bigwedge_{l=1}^{n} \operatorname{lit}\left(s[l], s_{i, j}[l]\right)$, onde $s[l] \in\{0,1\}$ é a valoração que representa o estado $s$, e $s_{i, j}[l] \in \mathcal{P} \mathcal{V}$ são as variáveis proposicionais que representam o estado $i$ do caminho $j$;

- $T\left(s_{i, k}, s_{j, k}\right):=\left\{\begin{array}{c}\bigvee_{m=1}^{|T|} t_{m} \\ \bigwedge_{\substack{m=1 \\(x, y) \in T}}^{\bigwedge_{l=1}^{n}\left(\neg t_{m} \vee \operatorname{lit}\left(x[l], s_{i, k}[l]\right)\right)} \\ \bigwedge_{\substack{n=1 \\ l=1}}^{n}\left(\neg t_{m} \vee \operatorname{lit}\left(y[l], s_{j, k}[l]\right)\right) \\ \wedge\left(t_{m} \vee \bigvee_{l=1}^{n} \operatorname{lit}\left(x[l], s_{i, k}[l]\right) \vee \bigvee_{l=1}^{n} \operatorname{lit}\left(y[l], s_{j, k}[l]\right)\right)\end{array}\right]$, onde $x[l], y[l] \in\{0,1\}$ são as valorações que representam o estado $x$ e $y$ do modelo, $t_{m} \in \mathcal{P} \mathcal{V}$ é a variável proposicional que representam esta transição, $s_{i, k}[l], s_{j, k}[l] \in \mathcal{P V}$ são as variáveis proposicionais que representam o estado $i$ e $j$ do caminho $k$;

- $p(w):=V\left(s_{i, j}, p_{i, j}\right):=\left\{\begin{array}{c}\left(\bigvee_{s: p \in V(x)} v\right) \wedge \\ \bigwedge_{s: p \in V(x)} D\left(v,\left(\bigwedge_{l=1}^{n} l i t\left(s[l], s_{i, j}[l]\right) \wedge p_{i, j}\right)\right)\end{array}\right.$, onde $x[l] \in\{0,1\}$ é a valoração que representa o estado $x, v, s_{i, j}[l], p_{i, j} \in \mathcal{P V}$, sendo que $s_{i, j}[l]$ são as variáveis proposicionais que representam o estado $i$ do caminho $j$, e $p_{i, j}$ é a variável que representa o valor de $p$ no estado $i$ do caminho $j$;

- $\neg p(w):=V\left(s_{i, j}, \neg p_{i, j}\right):=\left\{\begin{array}{c}\left(\bigvee_{x: p \notin V(x)} v\right) \wedge \\ \bigwedge_{x: p \notin V(x)} D\left(v,\left(\bigwedge_{l=1}^{n} \operatorname{lit}\left(x[l], s_{i, j}[l]\right) \wedge \neg p_{i, j}\right)\right)\end{array}\right.$, onde $x[l] \in\{0,1\}$ é a valoração que representa o estado $x$ e $v, s_{i, j}[l], p_{i, j} \in \mathcal{P} \mathcal{V}$, sendo que $s_{i, j}[l]$ são as variáveis proposicionais que representam o estado $i$ do caminho $j$, e $p_{i, j}$ é a variável que representa o valor de $p$ no estado $i$ do caminho $j$;

- $H\left(s_{i, k}, s_{j, k}\right):=\bigwedge_{l=1}^{n}\left(\neg s_{i, k}[l] \vee s_{j, k}[l]\right) \wedge\left(s_{i, k}[l] \vee \neg s_{j, k}[l]\right)$, onde $s_{i, k}[l], s_{j, k}[l] \in \mathcal{P} \mathcal{V}$ são as variáveis proposicionais que representam respectivamente o estado $i$ e $j$ do caminho $k$;

- $L_{i, k}(j):=T\left(s_{i, k}, s_{j, k}\right)$ que codifica um loop do estado $i$ para o estado $j$ no caminho $k$.

Definimos então a fórmula proposicional $\left[M^{\varphi, s_{0}}\right]_{k}$, onde $s_{0}$ é o estado inicial, como a tradução do modelo para lógica clássica:

$$
\left[M^{\varphi, s_{0}}\right]_{k}:=I_{s_{0}}\left(s_{0,0}\right) \wedge \bigwedge_{j=0}^{f_{k}(\varphi)-1} \bigwedge_{i=0}^{k-1} T\left(s_{i, j}, s_{i+1, j}\right)
$$

onde $s_{0,0}$ e $s_{i, j}$ para $i=0, \ldots, k-1$ e $j=0, \ldots, f_{k}(\varphi)-1$ representam os estados através dos $k$ - caminhos.

O próximo passo é traduzir a fórmula ECTL $\varphi$ para uma fórmula proposicional. Usaremos $[\varphi]_{k}^{[m, n]}$ para denotar a tradução de uma fórmula $\operatorname{ECTL} \varphi$ em $s_{m, n}$ (o estado $m$ do caminho $n$ ) para uma fórmula proposicional. Definimos a seguir essa tradução:

- $[p]_{k}^{[m, n]}:=p\left(s_{m, n}\right)$; 
- $[\neg p]_{k}^{[m, n]}:=\neg p\left(s_{m, n}\right)$;

- $[\alpha \wedge \beta]_{k}^{[m, n]}:=[\alpha]_{k}^{[m, n]} \wedge[\beta]_{k}^{[m, n]}$;

- $[\alpha \vee \beta]_{k}^{[m, n]}:=\left(a_{k}^{m, n} \vee b_{k}^{m, n}\right) \wedge D\left(a_{k}^{m, n},[\alpha]_{k}^{[m, n]}\right) \wedge D\left(b_{k}^{m, n},[\beta]_{k}^{[m, n]}\right)$;

- $\left[\begin{array}{lll}E X & \alpha\end{array}\right]_{k}^{[m, n]}:=\left\{\begin{array}{c}\left(\bigvee_{i=0}^{f_{k}(\varphi)-1} e x_{i}^{m, n}\right) \wedge \\ \bigwedge_{i=0}^{f_{k}(\varphi)-1} D\left(e x_{i}^{m, n}, H\left(s_{m, n}, s_{0, i}\right) \wedge[\alpha]_{k}^{[1, i]}\right)\end{array} ;\right.$

- $[E G \quad \alpha]_{k}^{[m, n]}:=\left\{\begin{array}{c}\left(\bigvee_{i=0}^{f_{k}(\varphi)-1} e g_{i}^{m, n}\right) \wedge \\ \bigwedge_{i=0}^{f_{k}(\varphi)-1} D\left(e g_{i}^{m, n}, H\left(s_{m, n}, s_{0, i}\right) \wedge\left(\bigvee_{l=0}^{k} L_{k, i}(l)\right) \wedge \bigwedge_{j=0}^{k}[\alpha]_{k}^{[j, i]}\right)\end{array} ;\right.$

- $[E(\alpha U \beta)]_{k}^{[m, n]}:=\left\{\begin{array}{c}\left(\bigvee_{i=0}^{f_{k}(\varphi)-1} e u_{i}^{m, n}\right) \wedge \\ \bigwedge_{i=0}^{f_{k}(\varphi)-1}\left(\bigwedge_{j=0}^{k} D\left(a b_{k}^{j, i},[\beta]_{k}^{[j, i]} \wedge \bigwedge_{t=0}^{j-1}[\alpha]_{k}^{[t, i]}\right) \wedge D\left(e u_{i}^{m, n}, H\left(s_{m, n}, s_{0, i}\right) \wedge \bigvee_{j=0}^{k} a b_{k}^{j, i}\right)\right) ;\end{array}\right.$

Denotemos $[\varphi]_{k}^{[0,0]}$ como $[\varphi]_{M_{k}}$.

\subsubsection{Verificação e Revisão}

Tendo em mãos a tradução da estrutura de Kripke $M^{k}$, onde $M^{k}=\left[M^{\varphi, s_{0}}\right]_{k}$, e da fórmula ECTL $A_{\varphi}^{k}$, onde $A_{\varphi}^{k}=[\varphi]_{M_{k}}$, precisamos rodar $M^{k} \wedge A_{\varphi}^{k}$ em um resolvedor SAT, onde $\psi$ é a fórmula ACTL a ser verificada e $\varphi \equiv \neg \psi$. Ao efetuarmos a verificação receberemos como saída uma resposta do resolvedor SAT sobre a satisfazibilidade desta forma. Com ela poderemos avaliar o modelo e caso necessário gerar as sugestões de mudança posteriormente.

Ao verificar uma fórmula $\psi$ em um modelo, utilizando BMC, queremos saber se a propriedade $\neg \psi$ vale naquele modelo. De fato, se $M \wedge \varphi$ são inconsistentes, significa que $M$ implica $\neg \varphi$. Então se $M^{k} \wedge A_{\varphi}^{k}$ é inconsistente, nada precisa ser feito com relação à revisão, e esse é o nosso caso ideal. Caso contrário, o resolvedor SAT irá gerar uma valoração $v$ que representa um caminho através de $M$ que satisfaz a fórmula $\varphi$.

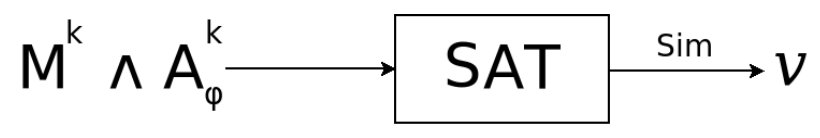

Figura 3.4: Verificação de modelos limitada requisitando revisão de crenças (Finger e Wassermann, 2008)

A revisão é feita ao transformar a valoração $v$ em mudanças no modelo, gerando uma fórmula proposicional $A_{\neg v}$. Entretanto pode ser o caso em que $M^{k} \wedge A_{\varphi}^{k} \wedge A_{\neg v}$ seja uma fórmula satisfeita por uma valoração $v_{2}$. Assim precisamos iterar $m$ vezes até que alcancemos uma fórmula $K^{\prime}$ inconsistente. Como o número de valorações é finito, o processo sempre termina.

$$
M^{\prime}=M^{k} \wedge A_{\varphi}^{k} \wedge A_{\neg v} \wedge \cdots \wedge A_{\neg v_{m}}
$$

Para negarmos uma valoração $v$ utilizamos um processo de escolha através de heurísticas. Primeiramente montamos o caminho representado pela valoração $v$ onde a fórmula $\varphi$ é satisfeita em 
uma estrutura de Kripke. Em seguida, percorremos este caminho marcando recursivamente se cada estado satisfaz $\varphi$ e suas subfórmulas, dessa forma procurando o estado onde $\varphi$ não é satisfeito. Tendo marcado todos os estados, percorremos novamente a estrutura aplicando o algoritmo de revisão.

A escolha do que deve ser feito em cada estado para satisfazer $\varphi$ é feita através de uma heurística recursiva para cada operador. As possíveis alterações a serem feitas na estrutura de Kripke que representa o caminho serão extendidas para a estrutura de Kripke que representa o modelo, gerando assim as alterações que devem ser feitas no modelo. Tais alterações serão descritas na próxima seção. O algoritmo de escolha e o padrão das heurísticas serão descritos mais detalhadamente na Seção 3.2 .

\subsubsection{Tradução reversa}

Aqui propomos uma forma de sugerir mudanças para o modelo inicial e traduzi-las da lógica clássica para a linguagem original, algo que não havia sido contemplado pelos trabalhos anteriores.

Durante o processo de verificação e contração, iremos encontrar valorações que representam um caminho no modelo que satisfaz $\varphi$, o qual devemos modificar para que falsifiquemos a fórmula. Para tal precisamos observar as seguintes variáveis proposicionais na tradução que representam o caminho:

- As variáveis de estado $s_{i, j}$ (ou seja todo o seu vetor), que representam o estado $i$ do caminho $j$

- As variáveis de transição $t_{m}^{i, i+1, j}$, que representam uma transição entre os estados $i, i+1$ do caminho $j$;

- As proposições $p_{i, j}$, que representam o valor de $p$ no estado $i$ do caminho $j$.

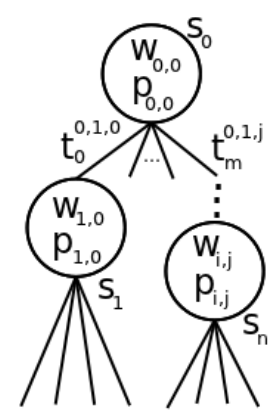

Figura 3.5: Variáveis utilizadas para gerar as sugestões

Essas variáveis identificam os diversos caminhos gerados pela CTL, no entanto com uma valoração deles, podemos identificar seus representantes no modelo original. Assim, a partir da valoração $v$ (observando as variáveis descritas acima) podemos reconstruir os caminhos dentro do modelo original.

Isso é feito principalmente através das variáveis de estado. Ao observarmos seu valor positivo ou negativo, sabemos identificar qual estado aquela posição no caminho representa. Isso pode ser melhor compreendido através do exemplo na Seção 3.3.

Com o caminho traduzido para o modelo original, podemos percorrer o mesmo procurando a falha e sugerindo mudanças no modelo. Essas mudanças podem ser feitas pelo usuário, selecionando sequencialmente cada uma das operações desejáveis, até que a propriedade seja válida no modelo. Ou podemos executar tal operação automaticamente, através do algoritmo de escolha com heurísticas que será descrito na Seção 3.2.

Existem 5 tipos de modificações unitárias, que requerem somente uma ação no modelo, que podem ser feitas à uma estrutura de Kripke, identificadas por (Zhang e Ding, 2008). 
- Modificar uma propriedade: Podemos mudar uma variável proposicional presente em um determinado estado para positiva ou negativa;

- Remover uma transição: Podemos remover uma transição entre dois estados;

- Remover um estado: Podemos remover um estado do modelo, mas para isto é necessário que este estado não possua nenhuma variável positiva ou qualquer transição. Se isto não for observado, estaremos eventualmente mudando uma propriedade ou removendo uma transição junto, fazendo com que esta ação não seja unitária;

- Adicionar uma transição: Criar uma nova transição entre estados;

- Adicionar um estado: Adicionamos um novo estado sem variáveis positivas ou transições.

Essas modificações foram implementadas da seguinte forma em nosso algoritmo no nível da fórmula proposicional:

- Modificar uma propriedade:

$$
\left.R_{p}(s)=\bigwedge_{j=0}^{f_{k}(\varphi)-1} \bigwedge_{i=0}^{k}\left[\bigvee_{l=0}^{n} \neg l i t\left(s[l], s_{i, j}[l]\right)\right) \vee \neg p_{i, j}\right]
$$

onde $s$ é a valoração do estado onde $p$ deve ser modificada.

- Remover uma transição:

$R_{t}(x, y)=\bigwedge_{j=0}^{f_{k}(\varphi)} \bigwedge_{i=0}^{k-1}\left[\bigvee_{l=0}^{n} \neg l i t\left(x[l], s_{i, j}[l]\right) \vee \bigvee_{l=0}^{n} \neg l i t\left(y[l], s_{i+1, j}[l]\right) \vee \neg t_{m}^{i, i+1, j}\right]$, onde $x$ e $y$ são as valorações dos estados que formam a transição a ser removida;

- Remover um estado vazio:

$R_{s}(x)=\bigwedge_{j=0}^{f_{k}(\varphi)-1} \bigwedge_{i=0}^{k} \bigvee_{l=0}^{n} \neg l i t\left(x[l], s_{i, j}[l]\right)$

onde $x$ é a valoração do vetor do estado a ser excluído;

- Adicionar uma transição: Para isto precisariamos modificar cada fórmula $T(w, v)$ para permitir mais uma transição. Como pode ser visto nas fórmulas de tradução, isso acarretaria uma grande mudança em toda a fórmula proposicional, devido a essa fórmula estar definida em vários pontos. Devido a esta complexidade, não implementamos esta opção neste momento.

- Adicionar um novo estado: A adição de um novo estado gera um problema na tradução, pois ela transforma um estado num conjunto de $n=\log (|K|)$ variáveis proposicionais. Se ao adicionarmos um novo estado ocorrer que $\log (|K|+1)>n$ teremos que refazer toda a tradução para satisfazer essa mudança. Isso causaria uma grande complexidade e retrabalho e por isso não foi implementado neste momento.

Desta forma, podemos revisar a fórmula proposicional ao mesmo tempo que guardamos as mudanças a serem feitas no modelo, retornando sugestões de mudança significativas para a especificação.

\subsubsection{Verificação final e iteração no tamanho dos caminhos}

Ao término do algoritmo, temos a especificação revisada e a fórmula ACTL $\phi$ vale na estrutura de Kripke até o limite $k$ estabelecido. No entanto pode ser que a fórmula ainda não seja satisfeita no modelo por um caminho de tamanho maior que $k$. Neste caso precisamos rodar o algoritmo novamente com um limite $k$ maior, isto é, o tamanho do caminho, até que a fórmula seja satisfeita no modelo como um todo.

Algumas abordagens podem ser adotadas para tratar a escolha do $k$, procurando encontrar o limite inicial ideal: 
- Podemos começar a partir de um $k$ baixo;

- Ou podemos utilizar um outro verificador de modelos para encontrar um caminho que falsifica a fórmula, definindo $k$ como o tamanho desse caminho.

Independente da escolha inicial, tratamos todos os casos com caminhos menores que $\mathrm{k}$ ao fazer uma verificação nesta profundidade, pois o verificador procura caminhos de tamanho $\mathrm{k}$ que possuem um erro, sendo este encontrado em qualquer parte do caminho. Com isso verificamos por erros no começo do caminho, e logo, para caminhos com tamanho menor que $k$. Iremos utilizar a primeira abordagem por questão de simplicidade, pois não precisamos utilizar outro verificador de modelos. Partiremos então de um $k$ baixo, incrementando $k$ até que o usuário determine quando parar. No entanto ainda é necessário termos um parâmetro para saber quando é suficiente parar de iterar para que tenhamos um modelo revisado.

A partir da função $K(\alpha)$ podemos determinar um valor para $k$, a partir do qual sabemos que a estrutura de Kripke esté completamente revisada para $\alpha$. Esse valor é o tamanho máximo de um caminho a partir do qual os caminhos maiores passam a se repetir e logo, já foram revisados. Para tal usaremos a constante $\varepsilon>0$ que representa o tamanho do maior caminho sem estados repetidos da estrutura de Kripke que representa o modelo. Podemos verificar que no pior caso $\varepsilon$ é igual ao número de estados na estrutura de Kripke.

Definimos a função $K(\alpha)$ da seguinte forma, para $\alpha$ uma fórmula em ACTL:

- $K(p)=K(\neg p)=K(p \wedge q)=1$

- $K(A X \alpha)=K(\alpha)+1$

- $K(A G \alpha)=K(A F \alpha)=K(\alpha)+\varepsilon$

- $K(A(\alpha \cup \beta))=K(\alpha)+K(\beta)+\varepsilon$

Podemos observar então que o limite $k$ necessário para se verificar uma estrutura de Kripke por uma fórmula $\psi$ é no pior caso $O(n * \varepsilon)$, onde $\varepsilon$ é o caminho mais longo da estrutura de Kripke sem loops, e $n$ é o número de operadores temporais aninhados.

\subsection{Algoritmo de escolha}

Após a verificação do modelo, podemos ter um caminho na estrutura de Kripke onde a fórmula a ser revisada é falsa. Então é necessário decidir qual tipo de alteração iremos fazer para que a fórmula passe a ser válida naquele caminho. Tal escolha pode ser feita pelo usuário, mas tal processo pode ser longo e confuso, portanto é desejável um processo automático de escolha, assim como o de verificação.

Propomos então uma estratégia de escolha a partir de heurísticas implementadas de acordo com o escopo do usuário. Um framework foi desenvolvido para o processo de revisão, deixando ao cargo da heurística implementada a escolha de qual alteração deve ser feita para cada operador a fim de tornar a fórmula verdadeira em determinado estado.

Iremos justificar a motivação por trás da escolha das heurísticas; mostrar como as heurísticas devem ser definidas; mostrar um exemplo de heurística; explicar como funciona o processo de revisão; e, as limitações da utilização de heurísticas.

\subsubsection{Necessidade de uma heurística}

Vimos na Seção 3.1.3 que podemos fazer 5 escolhas diferentes para alterar um modelo:

1. Modificar uma propriedade;

2. Remover uma transição; 
3. Adicionar uma transição;

4. Remover um estado vazio;

5. Adicionar um estado vazio.

Existe a necessidade de escolher qual dessas alterações iremos fazer no modelo a fim de tornar a fórmula a ser revisada válida. No entanto, em geral, vemos que cada uma dessas alterações possuem o mesmo peso sobre o modelo. Todas alteram uma parte do modelo, seja uma propriedade, uma transição ou um estado. Para um processo automático é necessário definir uma precedência entre tais operações para que uma escolha seja tomada.

O Princípio da Mudança Mínima (PMM) aconselha que a mudança no modelo seja a mínima possível, mas ainda é necessário definir o que é uma mudança mínima. Para cada situação de revisão podemos querer que determinada mudança ocorra o mínimo possível. Por exemplo, se trabalhamos com um modelo onde a configuração dos estados deve ser fixa, não é desejável adicionar ou remover um estado. Da mesma forma, se trabalhamos com um modelo onde a transição de um estado para outro é importante e não deve ser alterada, adicionar ou remover transições se torna indesejável. Logo, devemos definir para cada escopo o que significa satisfazer o PMM.

Assim, é necessário conhecer o escopo onde trabalhamos para que uma escolha seja tomada de qual operação deve ser executada. Isso faz com que não tenhamos uma resposta única, ou uma solução universal para decidirmos como modificarmos o modelo a ser revisado. Portanto diferentes soluções podem ser escolhidas para diferentes aplicações de acordo com o que se entende como mudança mínima.

Algumas estratégias podem ser escolhidas para abordar este problema. Uma delas seria criar uma ordem de precedência entre estas operações permitindo ao processo automático escolher qual a melhor modificação. Outra opção é definir uma estratégia de como alterar o modelo para revisar cada tipo de fórmula.

Decidimos seguir pela segunda opção por possuir uma estrutura mais flexível em relação à todo o processo de escolha e modificações, e, ao mesmo tempo por ser uma visão mais completa desse processo. Assim, definimos como heurística o conjunto de estratégias para resolver os conflitos no modelo para cada operador lógico e temporal.

\subsubsection{Definição de uma heurística}

Uma heurística é formada por dois componentes e uma restrição. Primeiramente devemos definir o PMM do escopo que iremos abordar. Tendo em vista o PMM, definimos as regras de alteração para cada operador lógico e temporal. Por fim, para uma heurística ser válida, as regras de alteração devem sempre satisfazer o $P M M$.

Como exemplos de $P M M$ temos como uma mudança mínima: o menor número de estados criados ou removidos, o menor número de transições criadas, e etc. Desta forma estamos definindo melhor como queremos alterar nosso modelo dentro do escopo do problema.

As regras de alterações definem como o modelo será alterado e quais operações básicas serão aplicadas quando encontramos uma falha. Essas regras devem ser criadas para cada operador, já que o processo de escolha funciona recursivamente. Como exemplos de regra de alteração para $A X a$ temos: acrescentar $a$ em todos os próximos estados, ou modificar as transições daquele estado de forma a todas levarem para um estado onde exista $a$.

Como visto, para cada escopo, determinada operação é menos ou mais desejada que outra. Assim definimos o PMM, e para que o mesmo seja válido as regras de alteração devem satisfazê-lo. Portanto, se temos um $P M M$ onde queremos o menor número de transições alteradas, a primeira regra de alteração para $A X a$ é válida, enquanto que a segunda não. Observando a regra de validação, temos que o processo de revisão satisfará o $P M M$ e dessa forma teremos um processo de revisão válido. 


\subsubsection{Exemplo de heurística}

Como exemplo de heurística usaremos uma onde apenas o valor das propriedades nos estados são alterados. Assim temos como $P M M$ manter a estrutura de estados e transições, executando o mínimo de mudanças nos valores das propriedades. Essa heurística é interessante para um contexto onde não queremos modificar os estados percorridos pelo modelo, nem alterar a estrutura de transições já definida para que o modelo satisfaça. Iremos descrever a seguir como essa heurística trata cada operador se há necessidade de uma correção, ou seja, as regras de alteração.

$A G \alpha$

Recursivamente chamamos o processo de revisão para $\alpha$ em cada um dos estados do caminho que se encontram após o estado atual.

\section{$A F \alpha$}

Recursivamente executamos o processo de revisão para $\alpha$ em cada estado posterior ao atual, vindo do estado mais distante para o mais próximo. A cada tentativa ficamos com a que retorna o menor número de alterações, sempre verificando se uma alteração em algum estado posterior garantiu que $A F \alpha$ valha no estado atual.

\section{$A(\alpha U \beta)$}

Se $\beta$ vale no estado, não fazemos nada. Caso contrário, garantimos que $\alpha$ valha no estado atual.

Em seguida verificamos se $\beta$ é válido em algum estado posterior ao que estamos, para cada caminho ramificado. Em caso positivo, recursivamente percorremos os caminhos garantindo que $\alpha$ valha em todos os estados até o estado onde $\beta$ vale. Caso contrário, recursivamente fazemos com que $\beta$ valha nos estados posteriores ao atual.

$A X \alpha$

Recursivamente chamamos o processo de revisão para $\alpha$ em cada um dos estados imediatamente seguintes ao estado a ser revisado.

\section{Operadores lógicos}

Verificamos se a fórmula lógica é satisfeita no estado. Caso contrário modificamos as valorações das propriedades a fim de que a fórmula se torne válida. Por exemplo, se temos $\alpha \equiv a \wedge b$ e $a$ é verdadeiro, enquanto $b$ é falso, modificamos $b$ para se tornar verdadeiro.

A restrição do $P M M$ é satisfeita pois não alteramos estados ou transições, e como alteramos uma propriedade só no estado lógico, já percorremos o caminho suficientemente para que quando chegarmos no estado em que uma alteração deve ser feita, ela será propagada para o restante do caminho, assim, não precisaremos fazer esta mesma alteração no restante do caminho.

\subsubsection{Processo de revisão}

Como entrada para o processo de revisão recebemos uma estrutura de Kripke contendo um caminho do modelo em que a propriedade a ser validada $\phi$ não é satisfeita. O processo de revisão utilizando heurísticas segue o seguinte algoritmo:

1. Percorremos todo o caminho rotulando-o com as subfórmulas de $\phi$;

2. Da mesma forma percorremos recursivamente o caminho verificando se $\alpha$ uma subfórmula de $\phi$ é válida;

3. Se $\alpha$ não é válida, o algoritmo aplica a regra de validação correspondente ao operador mais externo de $\alpha$; 
4. O algoritmo continua recursivamente na fórmula $\phi$, até que $\phi$ valha no modelo.

O algoritmo percorre o caminho de acordo com a necessidade imposta por cada operador lógico. Por exemplo, se precisamos garantir que $A X \alpha$ valha num determinado estado $s_{0}$, precisamos garantir que $\alpha$ valha em todos os estados seguintes à $s_{0}$. Dessa forma vamos percorrendo o caminho e corrigindo os erros marcados pelo processo de rótulo.

\subsubsection{Limitações do uso de heurísticas}

O uso de heurísticas possui uma limitação. Utilizamos um processo determinístico para revisar o modelo que, em geral, usa apenas um conjunto delimitado de operações. Isso faz com que fórmulas que só possam ser revisadas por algumas das operações deixadas de lado sejam dadas como insatisfazíveis. Por exemplo, uma fórmula que determine que a configuração das valorações em todo o modelo não seja alterada, não pode ser revisada por uma heurística que se utilize apenas de alterações nas propriedades do modelo. Um exemplo simples é tentarmos revisar o modelo abaixo com a seguinte fórmula:

$$
a \wedge A X b \wedge A F \neg b
$$

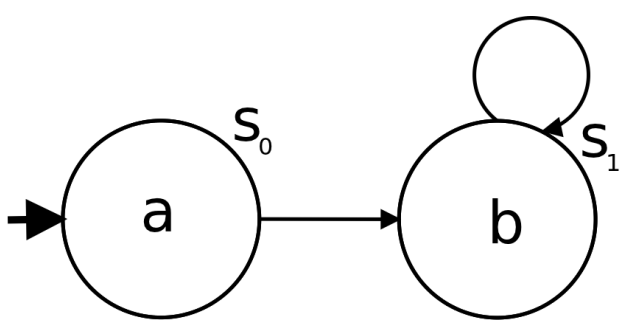

Figura 3.6: Exemplo de limitação

Como fixamos que $a$ deve existir no primeiro estado, e $b$ deve existir no segundo estado, não podemos alterar as valorações atuais. Já que não podemos criar novos estados ou mudar as transições, não temos como satisfazer $A F \neg b$.

No entanto, tal limitação vai de encontro com a escolha do escopo. Se desejamos revisar fórmulas no modelo que não podem ser satisfeitas pelas escolhas da heurística, temos uma heurística inadequada ao nosso escopo, sendo necessário uma melhor análise.

\subsection{Exemplo}

Até aqui temos utilizado o exemplo da máquina de busca. No entanto para deixar mais claro a execução do método nos utilizaremos de um exemplo mais simples e menor devido ao fato de usar um modelo como o da máquina de busca seria inviável por causa do tamanho das fórmulas.

Seja $M=(S, T, I, V)$ o modelo representado pela estrutura de Kripke abaixo, e $\psi=A G a$. Queremos revisar $M$ a respeito de $\psi$ e portanto verificar se $M \models A G a$.

Definimos nossa estrutura de Kripke da seguinte forma: $I=\left\{s_{0}\right\}, S=\left\{s_{0}, s_{1}\right\}, T=\left\{\left(s_{0}, s_{0}\right)\right.$, $\left.\left(s_{0}, s_{1}\right),\left(s_{1}, s_{1}\right)\right\}, V\left(s_{0}\right)=\{b\}, V\left(s_{1}\right)=\{c\}$ e $\varphi=\neg \psi=E(\top U \neg a)$ como a negação da fórmula que queremos revisar. Como $|S|=2$, precisamos de apenas uma variável para representar cada estado, assim a valoração de cada estado de $S$ será: $s_{0}=0$ e $s_{1}=1$. 


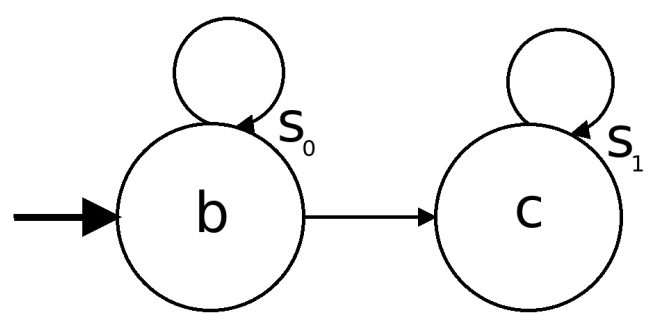

Figura 3.7: Exemplo básico

Iremos adotar $k=1$, pois isso simplifica nossas fórmulas e também podemos ver que é suficiente um caminho de tamanho 1 para verificar a fórmula.

Calculando $f_{k}(\varphi)$ temos:

$$
f_{1}(E(\top U \neg a))=1 * f_{1}(T)+f_{1}(\neg a)+1=1
$$

As fórmulas para a tradução do modelo ficam da seguinte forma:

$$
\begin{gathered}
{\left[M^{\varphi, s_{0}}\right]_{k}=I_{s_{0}}\left(s_{0,0}\right) \wedge T\left(s_{0,0}, s_{1,0}\right)} \\
I_{s_{0}}\left(s_{0,0}\right)=\neg s_{0,0} \\
T\left(s_{0,0}, s_{1,0}\right)=\left\{\begin{array}{c}
t_{0} \vee t_{1} \vee t_{2} \wedge \\
\neg t_{0} \vee \neg s_{0,0} \wedge \\
\neg t_{0} \vee \neg s_{1,0} \wedge \\
t_{0} \vee s_{0,0} \vee s_{1,0} \wedge \\
\neg t_{1} \vee \neg s_{0,0} \wedge \\
\neg t_{1} \vee s_{1,0} \wedge \\
t_{1} \vee s_{0,0} \vee \neg s_{1,0} \wedge \\
\neg t_{2} \vee s_{0,0} \wedge \\
\neg t_{2} \vee s_{1,0} \wedge \\
t_{2} \vee \neg s_{0,0} \vee \neg s_{1,0}
\end{array}\right.
\end{gathered}
$$

E a fórmula para a tradução da ECTL da seguinte forma:

$$
\begin{gathered}
{[E(T U \neg a)]_{1}^{[0,0]}=\left\{\begin{array}{c}
H\left(s_{0,0}, s_{0,0}\right) \wedge \\
\left(\alpha_{0,0} \vee \alpha_{1,0}\right) \wedge \\
D\left(\alpha_{0,0},[\neg a]_{1}^{0,0}\right) \wedge \\
D\left(\alpha_{1,0},[\neg a]_{1}^{1,0}\right)
\end{array}\right.} \\
H\left(s_{0,0}, s_{0,0}\right)=\left\{\begin{array}{c}
\neg s_{0,0} \vee s_{0,0} \wedge \\
s_{0,0} \vee \neg s_{0,0}
\end{array}\right. \\
D\left(\alpha_{0,0},[\neg a]_{1}^{0,0}\right)=\left\{\begin{array}{c}
\neg \alpha_{0,0} \vee \neg s_{0,0} \vee \neg a_{0,0} \\
\neg \alpha_{0,0} \vee \neg s_{0,0} \vee \neg a_{0,0} \\
\neg \alpha_{0,0} \vee \neg a_{0,0} \\
\alpha_{0,0} \vee s_{0,0} \vee a_{0,0} \\
\alpha_{0,0} \vee \neg s_{0,0} \vee a_{0,0}
\end{array}\right. \\
D\left(\alpha_{1,0},[\neg a]_{1}^{1,0}\right)=\left\{\begin{array}{c}
\neg \alpha_{1,0} \vee \neg s_{1,0} \vee \neg a_{1,0} \\
\neg \alpha_{1,0} \vee \neg s_{1,0} \vee \neg a_{1,0} \\
\neg \alpha_{1,0} \vee \neg a_{1,0} \\
\alpha_{1,0} \vee s_{1,0} \vee a_{1,0} \\
\alpha_{1,0} \vee \neg s_{1,0} \vee a_{1,0}
\end{array}\right.
\end{gathered}
$$

Para rodarmos as fórmulas acima num resolvedor SAT, iremos renomeá-las da seguinte forma:

$$
\begin{gathered}
s_{0,0}=1, s_{1,0}=2, a_{0,0}=3, a_{1,0}=4, \\
t_{0}=5, t_{1}=6, t_{2}=7, \alpha_{0,0}=8, \alpha_{1,0}=9
\end{gathered}
$$




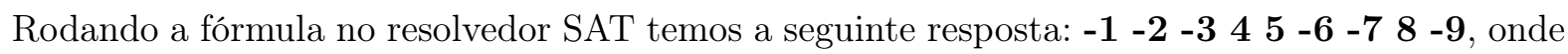
um número negativo significa que a variável proposicional é 0 e um valor positivo significa que a variável proposicional é positiva. Tal valoração representa o caminho descrito pela Figura 3.8, pois $s_{0,0}=0=s_{0}, s_{1,0}=0=s_{0}$.

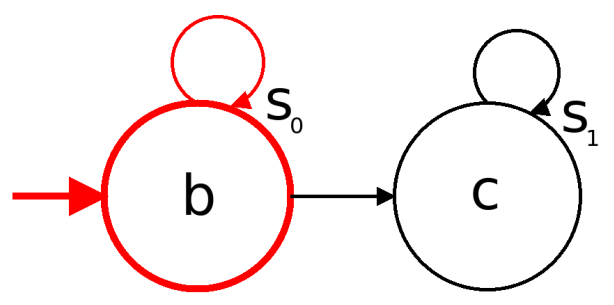

Figura 3.8: Primeira verificação

Inicialmente iremos verificar se $A G$ a vale no caminho segundo a heurística definida acima. Segundo a regra de alteração devemos verificar se $a$ vale nos estados, ou seja, é falso. Assim temos que fazer com que a valha no estado $s_{0}$. Para isso incluimos a seguinte fórmula no modelo:

$$
\left(s_{0,0} \vee a_{0,0}\right) \wedge\left(s_{1,0} \vee a_{1,0}\right)
$$

Com isso resultamos na estrutura de Kripke representada pela Figura 3.9.

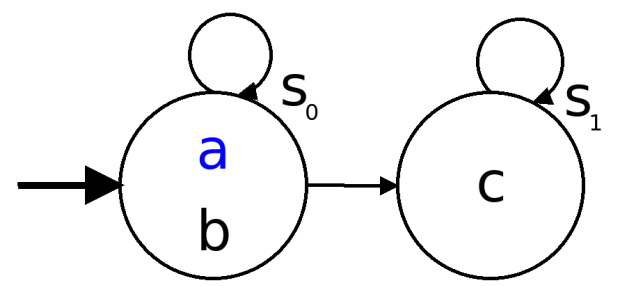

Figura 3.9: Resultado após a primeira mudança

Porém pode ser o caso de que a fórmula ainda não seja inconsistente, portanto rodamos o

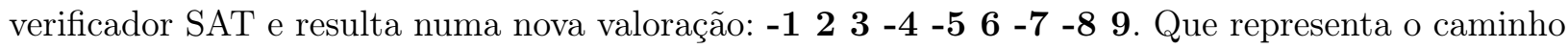
descrito pela Figura 3.11, pois $s_{0,0}=0=s_{0}, s_{1,0}=1=s_{1}$.

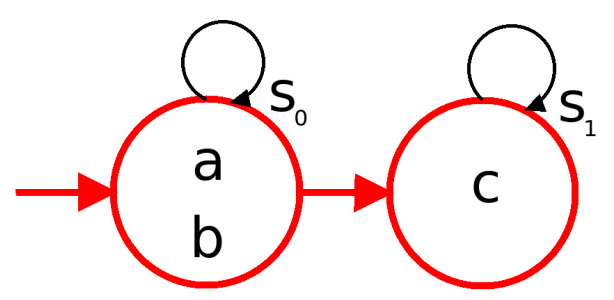

Figura 3.10: Segunda verificação

Devemos seguir novamente a heurística, verificando se $A G$ a vale neste caminho. Vemos que $a$ vale no estado $s_{0}$, mas quando verificamos no estado $s_{1}$, vemos que é falso. Portanto a heurística irá modificar o valor de $a$ no estado $s_{1}$, inserindo a fórmula abaixo.

$$
\left(\neg s_{0,0} \vee a_{1,0}\right) \wedge\left(\neg s_{1,0} \vee a_{1,0}\right)
$$

Resultando na estrutura de Kripke representada pela Figura 3.11. 


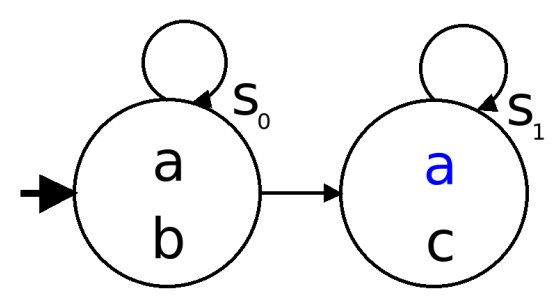

Figura 3.11: Inserção da propriedade a

O resolvedor SAT é chamado novamente para verificar se a fórmula ainda possui novos caminhos, resultando em falso. Como temos uma fórmula inconsistente sabemos que o processo de revisão chegou ao fim.

\subsection{Indecidibilidade e limitações da abordagem}

Como citado na Seção 2.4.5, (de Tarso Guerra Oliveira, 2016) demonstraram que o problema de Revisão de Crenças para lógicas temporais, entre elas CTL, é indecidível, ou seja, em geral, é impossível definir um operador de partial meet contraction como definido pela teoria AGM. Porém, eles mostraram que para conjuntos de fórmulas que podem ser definidos por modelos, e restringindo para fórmulas que expressam propriedades safety, o problema de indecidibilidade é evitado. Nossa abordagem de Revisão de Crenças utilizando Verificação de Modelos Limitada é um caso especial de revisão que satisfaz as restrições mostradas por (de Tarso Guerra Oliveira, 2016) para evitar o problema de indecidibilidade.

A entrada de nossa abordagem é uma estrutura de Kripke, desta forma nossa base de conhecimento por construção já é definida por um modelo bem estruturado. Como abordado na Seção 2.2.2, vimos que propriedades especificadas dentro do fragmento universal da CTL $(A C T L)$, são propriedades do tipo safety pois garantem que nada ruim aconteça no modelo. Portanto, é possível definir um operador de contração para nosso caso.

Além do resultado encontrado por (de Tarso Guerra Oliveira, 2016) mostrar que é possível o processo de revisão com nossa abordagem, (Finger e Wassermann, 2008) mostraram que a limitação no caminho a ser pesquisado e a subsequente tradução para lógica clássica permitem que a contração seja feita, já que iremos aplicá-la após a tradução sendo que segundo (Wassermann e Hansson, 1998) para lógicas compactas e monotônicas, como a lógica clássica, os operadores AGM podem ser aplicados.

Claramente essas restrições utilizadas em nosso algoritmo geram limitações. Como estamos limitando o tamanho dos caminhos, temos uma aproximação do modelo e portanto, como já abordado, não conseguimos garantir que as propriedades valem para o modelo como um todo, o que é compensado por diferentes iterações no tamanho de $k$. Outra limitação que temos é a restrição nas fórmulas a serem verificadas. Como apenas utilizamos $A C T L$ não temos como validar propriedades do tipo liveness, que garantem que algo eventualmente acontece, isto é, existe um caminho em que uma propriedade é válida. Porém como abordado nesta Seção, tais tipos de propriedades não são possíveis de serem contraídas do modelo, sendo que para provar tais propriedade seria necessário percorrer caminhos ilimitados o que pode levar um tempo indefinido, tornando-se praticamente inviável. Apesar disso, o uso de ACTL já é um avanço comparado à abordagem vista em (de Sousa, 2007) que não permite o encadeamento de operadores temporais. 


\section{Capítulo 4}

\section{Implementação e aplicação ao exemplo}

\subsection{Implementação do algoritmo}

Iremos aqui descrever sucintamente a implementação do algoritmo e quais as técnicas e estratégias utilizadas. $\mathrm{O}$ código em $\mathrm{C}++$ pode ser visto e baixado a partir do seguinte endereço: http://sourceforge.net/projects/br-bmc .

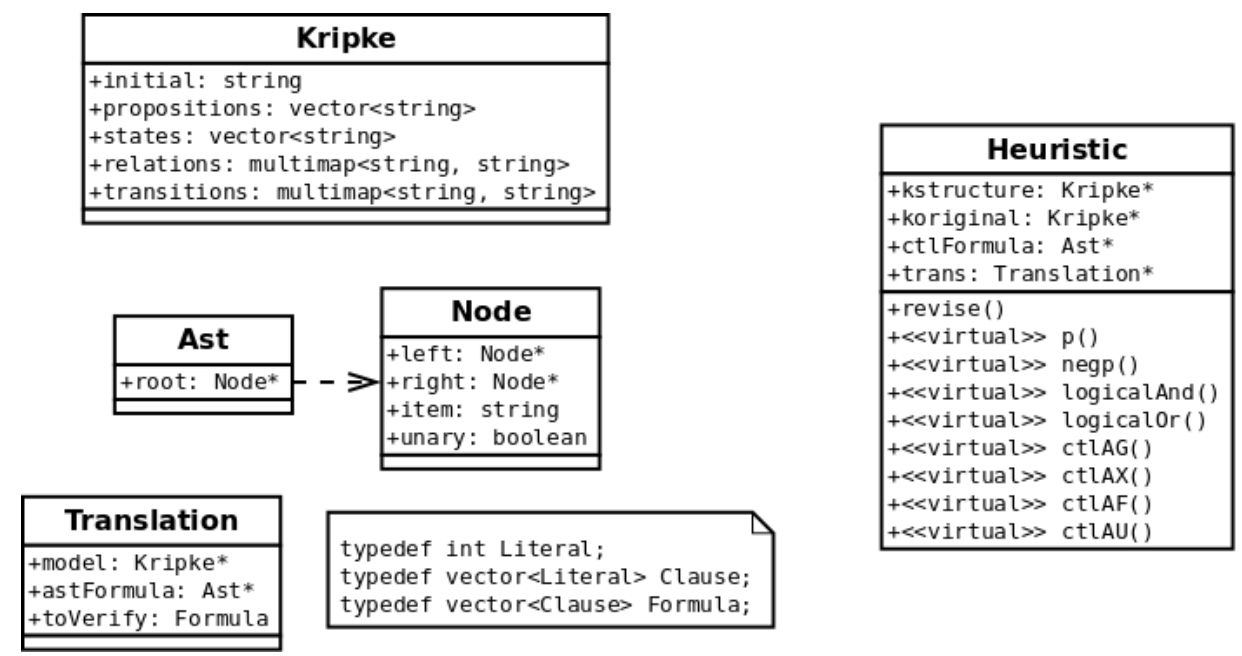

Figura 4.1: Diagrama de classes

Na Figura 4.1 temos a representação das principais classes da implementação:

- Kripke: é a classe que representa a estrutura de Kripke originada do modelo a ser verificado;

- Ast e Node: formam a estrutura de árvore que representa a fórmula ACTL a ser veficada;

- Translation: é a classe responsável por fazer a tradução e armazenar os objetos para a verificação;

- Formula, Clause e Literal: são as classes utilizadas para armazenar a fórmula proposicional originada da tradução;

- Heuristic: É a classe abstrata que determina os métodos necessários para a implementação de uma heurística, cada método virtual é a estratégia utilizada para revisar cada operador. 


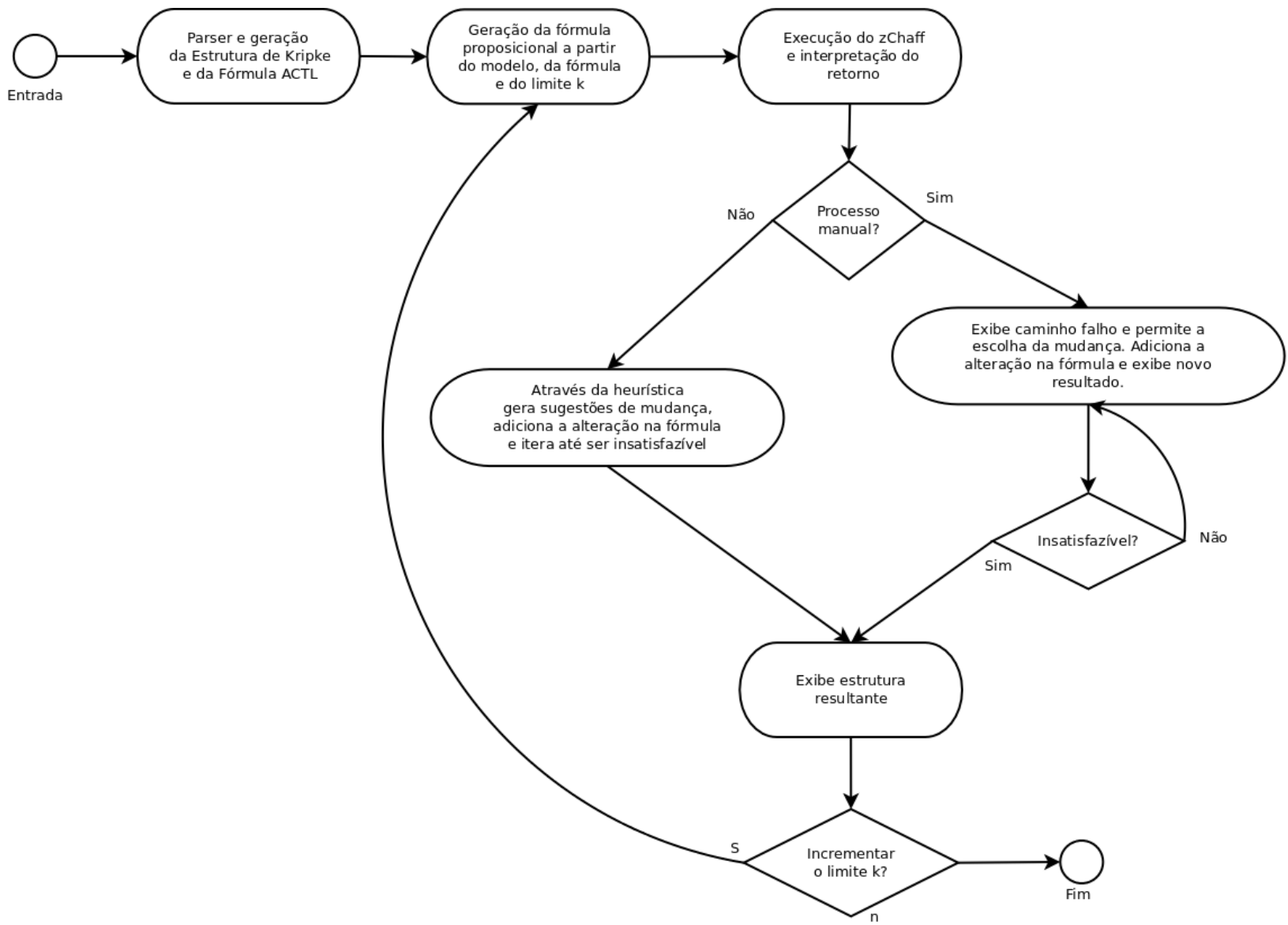

Figura 4.2: Fluxograma simplificado

Na figura 4.2 temos a representação do fluxograma simplificado da implementação do algoritmo. Após receber a estrutura e as propriedades a serem verificadas, o algoritmo faz toda a tradução e verificação através do resolvedor SAT $z$ Chaff (https://www.princeton.edu/c̃haff/zchaff.html), o qual pode ser facilmente trocado por outra implementação de um resolvedor SAT. Após a verificação temos duas possibilidades: escolher as alteração manualmente ou utilizar o processo automático através da heurística. No caso manual, será apresentado o caminho falho e o usuário pode escolher as modificações desejadas. Esse processo se repete até que o resolvedor SAT retorne que a fórmula é insatisfazível, isto é, que não existem mais contra-exemplos. No caso automático, o algoritmo irá analisar o resultado da verificação e, através da heurística, irá sugerir alterações no modelo. Esse processo itera automaticamente até que a fórmula esteja insatisfazível.

Com as sugestões de mudança, tanto manuais, quanto automáticas, a nova estrutura do modelo é exibida, permitindo a possibilidade de aprofundar o tamanho dos caminhos. Em caso positivo, o sistema irá incrementar o tamanho máximo do caminho e recomeçar o processo de tradução e verificação. Em caso negativo o algoritmo finaliza. Nas próximas seções iremos descrever melhor cada uma dessas etapas.

\subsubsection{Entrada}

A entrada atualmente é feita através de uma estrutura de Kripke, representada por um arquivo de texto. Este arquivo é lido e armazenado dentro de um objeto da classe Kripke. As propriedades temporais são escritas em outro arquivo texto, usando a própria sintaxe da ACTL. Este arquivo é lido e interpretado pelos analisadores léxico e sintático, flex (https://github.com/westes/flex) e bison (https://www.gnu.org/software/bison/), sendo transformados em uma árvore de sintaxe. Pode ser inserido um valor inicial para $\mathbf{k}$ (juntamente com o modelo e a propriedade), caso contrário, será usado $k=1$.

$\mathrm{O}$ arquivo de entrada é definido da seguinte forma: 
- Um inteiro M, seguido de N proposições existentes no modelo;

- Um inteiro N, seguido de M estados, seguidos de M linhas onde são descritas as proposições (separadas com espaço) em cada estado;

- Um inteiro P, seguido de P transições, onde s0 s1 significa a transição de s0 para s1;

- Finalmente o estado inicial.

Desta forma, nosso exemplo de uma máquina de busca é representado da seguinte forma:

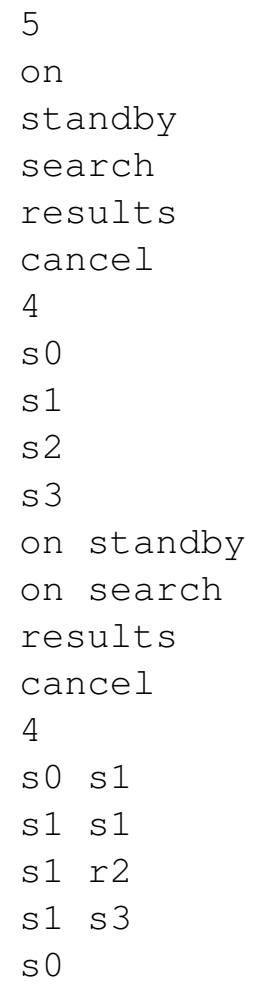

Resultado dos arquivos de entrada já tratados:

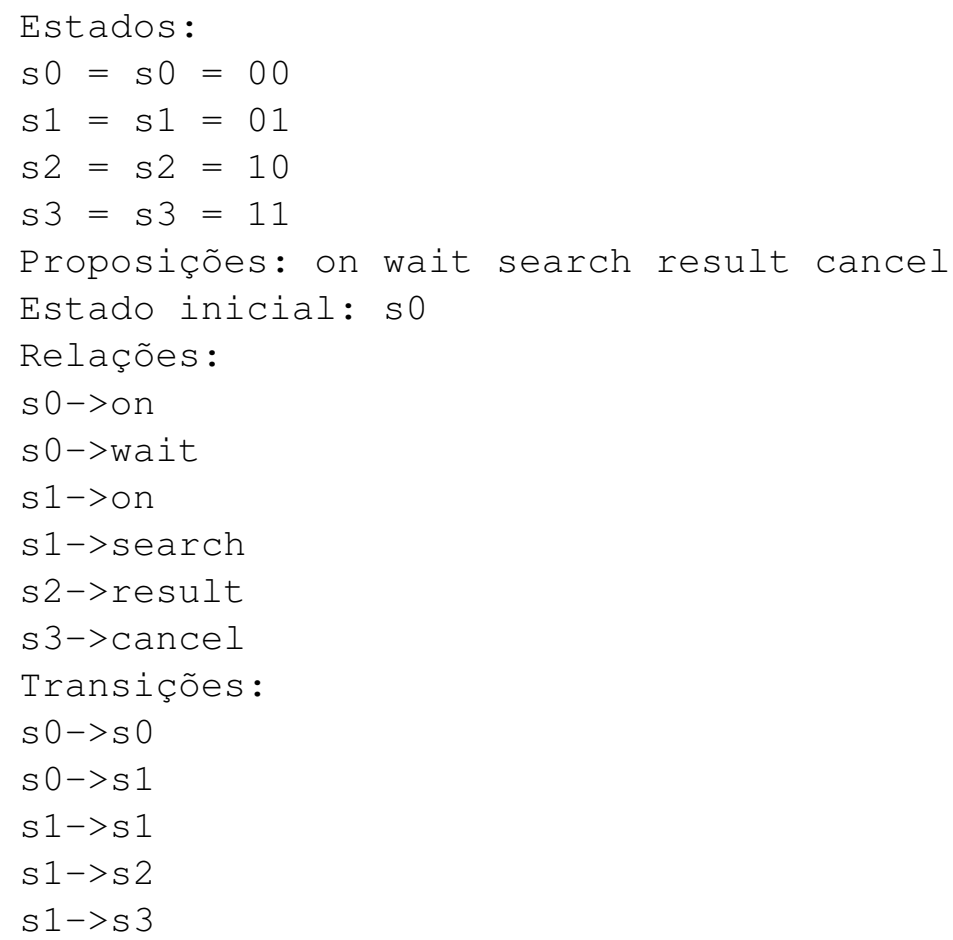




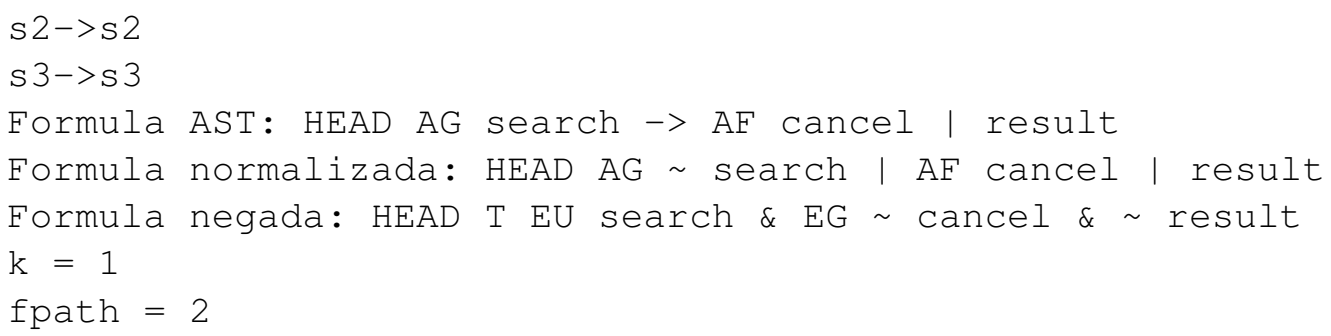

\subsubsection{Tradução e verificação inicial}

Usando as fórmulas apresentadas anteriormente, transformamos a estrutura de Krikpe em fórmulas proposicionais CNF que são armazenadas numa matriz de inteiros. Cada linha representa uma cláusula (uma sentença formada apenas por OU lógicos). Nela são inseridas um número que representa uma variável proposicional. Para facilitar o acompanhamento de uma visualização da fórmula, um dicionário é criado relacionando cada número com o nome da variável. Como queremos achar um caminho em que a propriedade é válida, iremos negá-la para que seja verificada sua negação no resolvedor SAT. Então, a partir da árvore sintática da fórmula ACTL negada (uma fórmula em ECTL agora), geramos mais fórmulas proposicionais CNF, anexando-as à matriz com as fórmulas da estrutura de Kripke. Assim, ao final, temos uma grande matriz contendo uma fórmula em CNF a ser verificada.

A fórmula é impressa num arquivo texto .cnf que através de comandos bash será executada num resolvedor SAT, no caso, o zChaff. (O resultado do resolvedor SAT é parseado, retirando-se apenas o resultado e a valoração caso SAT.) O resolvedor SAT é facilmente trocado, pois o mesmo é executado através de um script na linha de comando. Assim seria possível fazer a troca para outra implementação, desde que seja feito um pequeno ajuste no código para fazer o parse do retorno dessa nova versão. Se temos um resultado UNSAT, significa que a negação da fórmula ACTL não é válida no modelo para $\mathrm{k}$, isto é, a propriedade é válida. Se temos um resultado $S A T$, teremos uma valoração que satisfaz a fórmula, ou seja, temos um caminho (descrito através da valoração) onde a negação da fórmula não é válida, e portanto, a propriedade a ser revisada não é válida.

\subsubsection{Tradução reversa, contração e verificação final}

A partir da valoração, usando o dicionário, identificamos quais estados representam o caminho através do valor das $k * \log _{2}(n)$ primeiras variáveis, onde $\mathrm{k}$ é a profundidade do caminho e $\mathrm{n}$ é o número de estados. Todos os estados ordenados são representados por um número binário, ou seja, o primeiro estado será 00, o segundo 01 e assim em diante. Com isso conseguimos identificar o caminho onde a propriedade não é válida, permitindo que a revisão possa ser feita.

Uma estrutura de Kripke é criada através dos caminhos indicados pelo processo de verifição. Os diferentes caminhos são unidos ao juntar o primeiro estado de cada caminho adicional a um estado do caminho principal que começa no estado inicial. Essa estrutura de Kripke é então utilizada para encontrar o erro e decidir qual mudança deve ser feita.

Retorno da verificação seguindo o exemplo anterior:

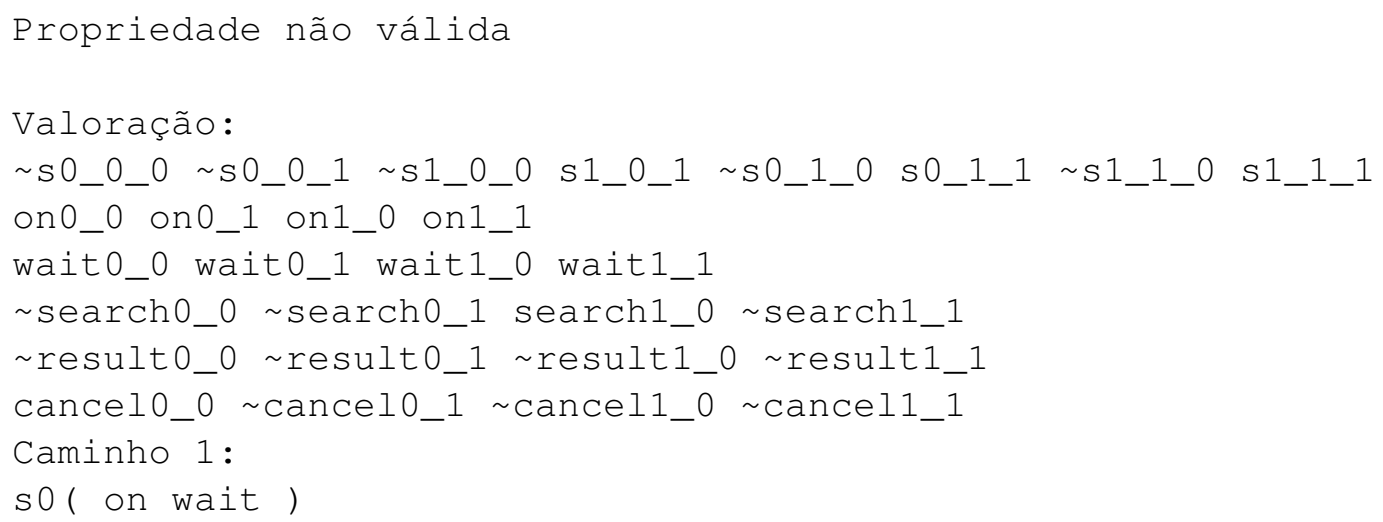




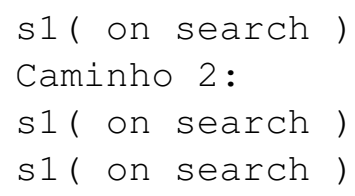

Há duas possibilidades para a decisão, manual ou automática. Caso o usuário decida fazer a correção manualmente, ele deve escolher uma das opções abaixo, identificando os estados ou proposições envolvidas na mudança. Se o usuário decidir por um método de decisão automático, então o programa usará uma das heurísticas implementadas e decidirá entre as mesmas opções listadas abaixo.

- Adicionar um estado (não implementado);

- Remover um estado;

- Adicionar uma transição (não implementado);

- Remover uma transição;

- Modificar o valor de uma proposição num determinado estado.

Tendo feita a escolha, o programa acrescentará uma das fórmulas descritas à fórmula CNF do modelo. Em seguida o script irá rodar o resolvedor SAT novamente, repetindo o processo descrito acima até que tenhamos um resultado UNSAT. Por fim, o programa irá fazer as alterações na estrutura de Kripke, imprimindo para o usuário as especificações da estrutura ao final da revisão.

Resultado final da execução do programa:

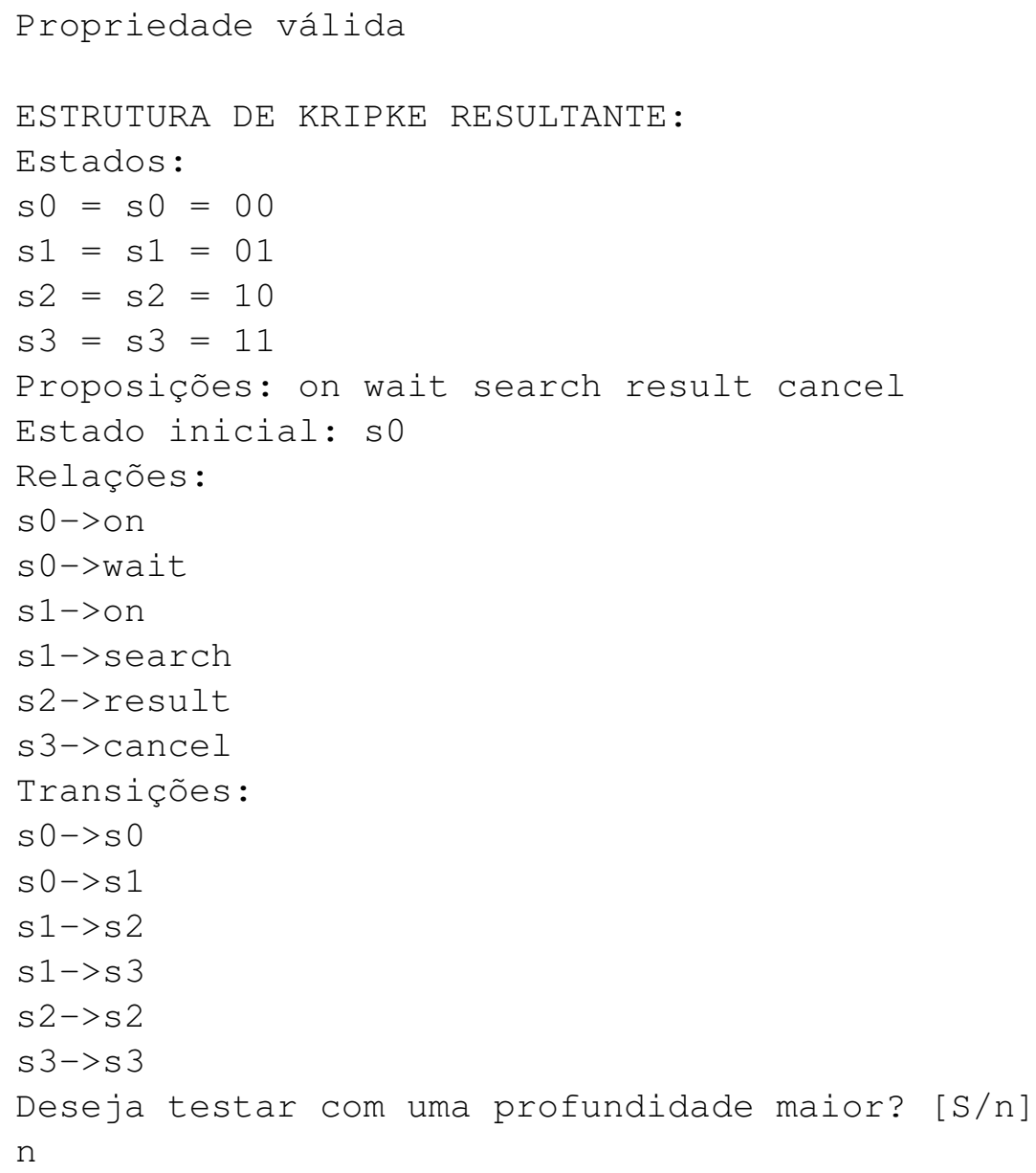

Caso seja feita a correção automática, o algoritmo da heurística irá sugerir mudanças no modelo e iterar até que a fórmula CNF seja insatisfazível e, logo, a propriedade seja satisfazível. Neste caso, além da estrutura restante, será exibido um log das mudanças a serem feitas na estrutura. 
Mudanças a serem feitas:

- Mudar o valor da proposição result em s1

\subsubsection{Heurísticas}

As heurísticas foram implementadas através de uma classe abstrata. Essa classe abstrata contêm implementados os métodos recursivos para rotular todo o caminho com as subfórmulas de $\phi$, a fórmula a ser validada; e, o método recursivo para revisar a fórmula $\phi$ através do modelo. Além disso, essa classe contêm os métodos para cada operador lógico e temporal que devem ser implementados para que a revisão ocorra. Vide Figura 4.1 para uma descrição da classe abstrata Heuristic.

Esses métodos recebem uma subfórmula $\alpha$ de $\phi$ e o estado $s$ onde essa fórmula deve ser validada. É então verificado se $s$ satisfaz $\alpha$, senão, a heurística define como o modelo será alterado, se necessário, chamando recursivamente um método para revisar uma subfórmula de $\alpha$. O processo continua até que $\phi$ seja válido no modelo.

A heurística descrita no capítulo anterior foi implementada e tem como princípio apenas modificar as propriedades existentes, sem modificar o conjunto de estados ou transições. Assim, temos os seguintes comportamentos para cada método da classe Heuristic implementados:

- p: se o estado atual não possui a variável proposicional verificada, adiciona a variável ao estado, isto é, muda ela para verdadeiro. Caso contrário, retorna as alterações até o momento.

- negp: se o estado atual possui a variável proposicional verificada, remove a variável do estado, isto é, muda ela para false. Caso contrário, retorna as alterações até o momento.

- logicalAnd: verifica se ambas as fórmulas são satisfeitas naquele estado. Caso alguma delas, ou ambas, não sejam satisfeitas, recursivamente chama o método para revisar a fórmula não satisfeita naquele estado.

- logicalOr: verifica se uma das duas fórmulas é satisfeita naquele estado. Caso ambas não sejam satisfeitas, recursivamente chama o método para revisar cada fórmula naquele estado e escolhe a fórmula que gera a menor mudança para se tornar válida.

- ctlAG $(A G \alpha)$ : verifica se a fórmula $\alpha$ contida no operador AG é satisfeita em cada estado posterior ao estado atual no caminho. Caso não seja válido em algum dos estados, revisa $\alpha$ naquele estado através do respectivo método.

- ctlAX $(A X \alpha)$ : verifica se a fórmula $\alpha$ contida no operador AX é satisfeita no estado seguinte ao estado atual no caminho. Caso não seja válido no estado seguinte, revisa $\alpha$ naquele estado através do respectivo método.

- ctlAU $(A(\alpha U \beta))$ : se o estado atual satisfaz $\beta$, nada precisa ser feito. Caso contrário verifica se algum estado posterior ao estado atual satisfaz $\beta$. Neste caso, os estados entre o estado atual e o estado que satisfaz $\beta$ são revisados a respeito de $\alpha$. Caso nenhum estado do caminho satisfaça $\beta$, então o estado atual é revisado a respeito de $\beta$.

- $\operatorname{ctlAF}(A F \alpha)$ : verifica se a fórmula $\alpha$ é satisfeita em algum dos estados posteriores ao estado atual no caminho. Caso nenhum estado satisfaça a fórmula, revisa $\alpha$ em cada um dos estados posteriores no caminho e seleciona a mudança mínima entre elas.

No próximo capítulo, iremos apresentar os experimentos efetuados utilizando esta heurística e analisar os resultados em relação à complexidade dos exemplos e ao tempo necessário para gerar as sugestões. 


\section{Capítulo 5}

\section{Experimentos e análise}

\section{$5.1 \quad$ Experimentos}

Para avaliar o uso e eficiência da solução, executamos alguns testes e avaliaremos alguns dados. Nesta Seção iremos descrever os exemplos utilizados e os testes executados, assim como listar os resultados. Deixaremos para a próxima Seção a explicação dos dados coletados.

\subsubsection{Exemplo básico}

Este é o mesmo exemplo usado na Seção 1.4. Com ele podemos ver a execução automática do exemplos detalhado.

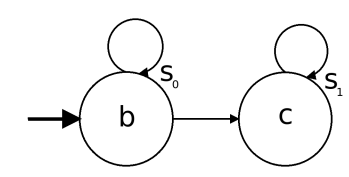

Figura 5.1: Estrutura de Kripke para o exemplo

O seguinte teste foi realizado com os respectivos resultados:

Fórmula: $A G(a)$

Valor de k: 1

Tempo de execução: $0.3 \mathrm{~s}$

Número de variáveis: 100

Número de cláusulas: 220

Mudanças:

- Mudar o valor da proposição a em s0

- Mudar o valor da proposição a em s1

\subsubsection{Máquina de busca}

Foram executados testes no nosso exemplo da máquina de buscas. Os seguintes testes foram realizados, utilizando $\mathrm{k}=4$, com os respectivos resultados: 


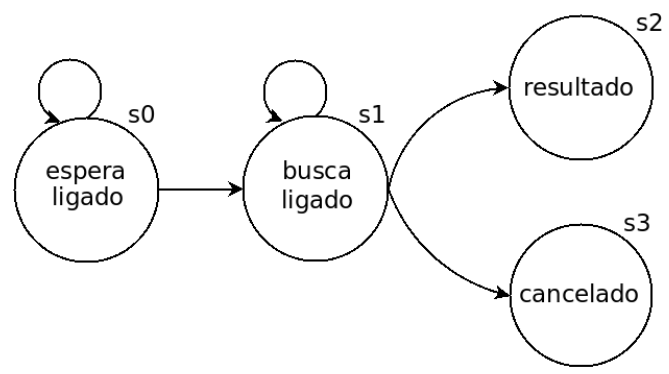

Figura 5.2: Máquina de busca

Fórmula: $A G($ search $\rightarrow A F($ cancel $\vee$ result $)$

Tempo de execução: $30 \mathrm{~s}$

Número de variáveis: 10744

Número de cláusulas: 35725

Mudanças:

- Mudar o valor da proposição result em s1

Fórmula: $A G($ wait $\rightarrow A X$ search $)$

Tempo de execução: $1 \mathrm{~s}$

Número de variáveis: 1564

Número de cláusulas: 4105

Mudanças:

- Mudar o valor da proposição search em s0

Fórmula: $A G(($ cancel $\vee$ result $) \rightarrow A X$ wait $)$

Tempo de execução: $3 \mathrm{~s}$

Número de variáveis: 2382

Número de cláusulas: 6143

Mudanças:

- Mudar o valor da proposição wait em s2

- Mudar o valor da proposição wait em s3

Fórmula: $A G(A($ on $U$ (result $\vee$ cancel $))$

Tempo de execução: $5 \mathrm{~m} 51 \mathrm{~s}$

Número de variáveis: 37474

Número de cláusulas: 107585

Mudanças:

- Mudar o valor da proposição result em s1

- Mudar o valor da proposição result em s0

Este último exemplo serve para mostrar a vantagem no uso incremental de k. Iremos executar o mesmo exemplo, no entanto começando com um $\mathrm{k}=1$ e incrementando até que $\mathrm{k}=4$.

Fórmula: $A G(A($ on $U$ (result $\vee$ cancel $))$

Limite k: 1 até 4

Tempo de execução total: $2 \mathrm{~m} 4 \mathrm{~s}$

Mudanças:

- Mudar o valor da proposição result em s1

- Mudar o valor da proposição result em s0 


\subsubsection{LCS (The Light Control System)}

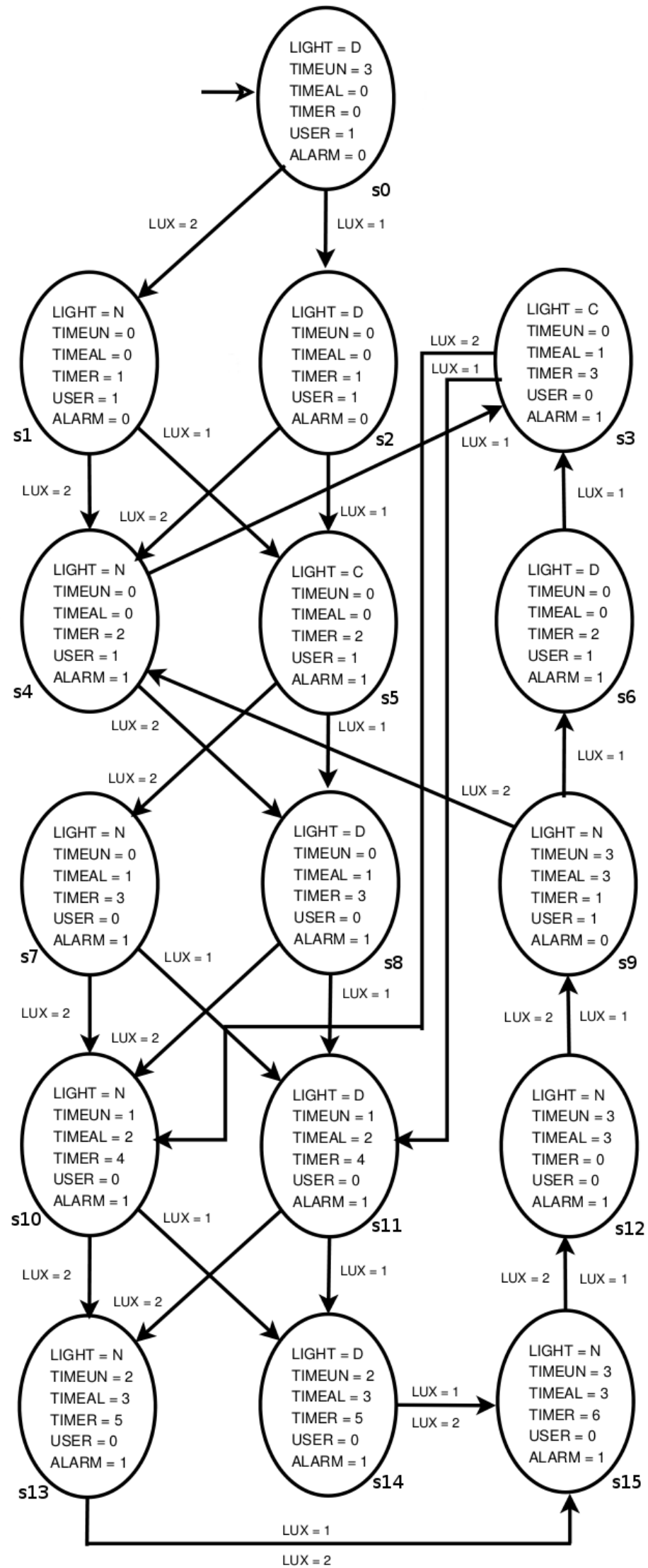

Figura 5.3: $L C S$ 
Esse exemplo é o mesmo apresentado por (de Sousa, 2007), vide Figura 5.3. Ele é uma modelagem de um sistema de controle de iluminação de um prédio, onde temos os seguintes requisitos:

- O sistema possui 3 tipos de iluminação: iluminação padrão (d), iluminação escolhida pelo usuário (c) e sem iluminação (n).

- O sistema também controla o tempo que o prédio está desocupado e o tempo que o alarme está disparando.

- Quando a luz externa for muito forte a iluminação é suspensa. Se a luz externa é razoável para o ambiente e a iluminação foi escolhida pelo usuário, a iluminação padrão é estabelecida.

- Sempre que um usuário entrar no prédio, a iluminação padrão é estabelecida. Entretanto, se um usuário entrar no prédio antes de um tempo mínimo para reocupação, a iluminação é estabelecida de acordo com a escolha do usuário anterior. Se o tempo mínimo para reocupação expirar, a iluminação é suspensa.

- Quando o alarme é disparado e já se passou um determinado tempo, a iluminação é suspensa. Caso contrário, a iluminação padrão é estabelecida.

A partir dos requisitos acima, o sistema foi modelado da seguinte forma:

- uma variável para representar os 3 tipos de iluminação (light).

- três variáveis de relógios (timeun para contar o tempo de desocupação, timeal para contar há quanto tempo o alarme está disparando e timer que será utilizado para simular eventos).

- duas variáveis para simulação de eventos (user para detectar a presença de pessoas e alarm para detectar que há fogo).

- uma variável sensorial (lux para verificar a luminosidade externa).

Gerando assim a estrutura de Kripke representada pela Figura 5.3.

A fórmula que iremos verificar é a seguinte:

$$
A G(((\text { timeun }<3 \wedge \text { user }) \rightarrow \text { light }=c) \wedge(\text { timeun }=3 \rightarrow \text { light }=n))
$$

Ela tem como objetivo garantir globalmente que se o tempo de desocupação (timeun) é menor que 3 e o usuário (user) está presente, então a iluminação (light) é a escolhida pelo usuário (c). E quando o tempo de desocupação chegar a 3, e o usuário não estiver mais presente, então a luz deve ser desligada $(n)$.

Como na lógica proposicional não temos os operadores de $=$, então modelamos cada igualdade como uma variável proposicional, logo, a variável TIMEUN1 significa que timeun $=1$ e por sua vez, LIGHTN significa que light $=n$.

Fórmula: $A G((((T I M E U N 1 \vee T I M E U N 2) \wedge U S E R) \rightarrow L I G H T C) \wedge(T I M E U N 3 \rightarrow$ LIGHTN $) \wedge$ $((\neg L I G H T N \wedge \neg L I G H T C \wedge L I G H T D) \vee(\neg L I G H T D \wedge \neg L I G H T C \wedge L I G H T N) \vee(\neg L I G H T N \wedge$ $L I G H T C \wedge L I G H T D)))$

Limite k: iteração de 1 até 18 (resolvido em $\mathrm{k}=1$ )

Tempo de execução: $19 \mathrm{~m} 3 \mathrm{~s}$

Número de variáveis: 24470

Número de cláusulas: 68519

Mudanças:

- Mudar o valor da proposição LIGHTN em s0

- Mudar o valor da proposição LIGHTD em s0

Desta forma a solução proposta pelo algoritmo é alterar o valor da variável light para $n$ no estado inicial. 


\subsection{Análise da performance}

\subsubsection{Tamanho da fórmula}

Vemos através dos exemplo que conforme a complexidade do modelo aumenta, o tamanho da fórmula SAT acompanha. Há três fatores principais que influenciam no aumento dos tamanhos da fórmula, tendo em vista o algoritmo de tradução descrito na Seção 3.1.1:

1. Número de estados;

2. Complexidade dos operadores temporais;

3. Níveis de operadores temporais aninhados.

Iremos discorrer sobre eles a seguir.

\section{Número de estados}

Conforme o número de estados aumenta, o número de variáveis proposicionais para os representar aumenta o que acarreta em maior número de variáveis. Isso também reflete na quantidade de cláusulas pois para representar cada uma das fórmulas precisamos iterar em mais variáveis por estado.

\section{Complexidade dos operadores temporais}

Cada operador temporal requer uma fórmula diferente, algumas maiores ou mais complexas. Isso reflete a quantidade de estados e opções que devem ser verificadas para validar a fórmula. Assim, operadores com fórmulas maiores e mais complexas aumentam a quantidade de variáveis (principalmente devida a redefinição de variáveis) e de cláusulas.

\section{Níveis de operadores temporais aninhados}

Podemos observar nas fórmulas descritas que ao avaliar cada operador, é necessário avaliar a fórmula contida nele. Assim, se a fórmula interna for de maior complexidade ou requerer maior nível de análise, o tamanho da fórmula SAT irá aumentar.

\subsubsection{Tempo}

Um fator muito importante observado na variação do tempo é o impacto que a execução do SAT Solver teve. Como vimos o aumento da complexidade da estrutura e da fórmula tem um impacto importante na fórmula. Podemos ver que com o aumento do tamanho das fórmulas SAT, houve um aumento do tempo de execução. Os testes mostraram que o maior tempo de espera é no momento de uma verificação no SAT solver, enquanto aguardamos o resultado das modificações.

\subsubsection{Sugestões}

Em nossos exemplos, as sugestões resultaram em alterações efetivas no modelo. Mas podemos ver também que muitas das soluções não geraram as alterações desejadas ou que se mostrariam mais lógicas aos nossos olhos. Isso se deve pela escolha da heurística e pela sua simplicidade, o que vai de acordo com nosso argumento sobre a importância da escolha certa da heurística.

\subsection{Análise geral}

Os testes mostraram que o algoritmo de Revisão de Crenças usando Verificação de Modelos Limitada é possível. Isso confirma a sugestão teórica levantada por (Finger e Wassermann, 2008) e a implementação proposta por este trabalho. Os resultados dos testes, apesar de pequenos, resultaram 
em tempos de execução aceitável, e combinados com uma estratégia de execução incremental se torna uma boa ferramenta para tratar de problemas maiores e mais complexos.

Outro fator importante foi a análise da abordagem escolhida de utilizar heurísticas. Vimos que a abordagem funciona bem e que gera resultados válidos para o processo de revisão automática. Comprovamos também a necessidade de uma abordagem mais específica para cada escopo a fim de gerar soluções mais válidas lógicamente durante a revisão. Apesar da heurística ter gerado sugestões de mudança que tornavam as fórmulas válidas, ela gerou sugestões que visivelmente não seriam muito aceitáveis.

Isso nos leva a uma última análise: há a possibilidade de melhorarmos a fórmula a fim de impedirmos que sugestões indesejáveis sejam feitas, através de uma conjunção de fórmulas restritivas. Mas isto acarreta em duas desvantagens:

- O aumento da complexidade da fórmula acarreta num aumento do tempo de execução;

- Podemos especificar demais a fórmula a ponto de tornar a heurística com suas restrições inviável.

Obviamente para uma melhor análise e um teste mais eficaz da especificação, requer mais tempo de processamento da revisão. Já as restrições da heurística podem ser contornados com uma heurística mais eficaz, fato proporcionado por esta liberdade de usar sua própria solução. Essas restrições serão levantadas e detalhadas mais a seguir.

\subsubsection{Restrições}

Nossa implementação apresenta algumas restrições que iremos listar a seguir:

- Uso da linguagem ACTL;

- Opção de criação de novos estados;

- Qualidade das heurísticas;

- Formato de entrada.

Como descrevemos e explicamos anteriormente, decidimos por usar a ACTL como linguagem temporal, o que nos permitiu executar a verificação de modelo limitada. Mas essa escolha impede que utilizemos operadores temporais do tipo existencial (EG, EX, EF e EU). Isso restringe inicialmente as fórmulas que podemos testar, mas como defendido anteriormente, essa escolha não é tão prejudicial. Uma vantagem, em relação a implementação de (de Sousa, 2007), que ganhamos ao utilizar essa abordagem é a possibilidade de aninhar operadores temporais dentro de operadores temporais, aumentando a complexidade das fórmulas.

Na tradução do modelo para uma fórmula SAT usamos a estratégia de identificar cada estado como uma valoração de $m$ variáveis, onde $m=\log _{2} n$ e $n$ é o número de estados. Ao fazer isso, como pode ser visto na declaração de cada fórmula, toda fórmula SAT ficará dependente do valor de $m$. Portanto se adicionarmos um estado fazendo com que $\log _{2} n>m$ teremos que refazer toda a tradução do modelo para SAT. Por isso, decidimos não implementar essa opção de mudança pelo nível de complexidade.

Algo que determina o nível das sugestões e o tipo da fórmula a ser testada é a qualidade da heurística implementada. Ao disponibilizarmos esse framework para utilização da sua própria heurística, deixamos as decisões da revisão no autor da heurística. Se a heurística não for bem implementada não teremos boas sugestões. Além disso, se uma heurística executar um conjunto restrito de alterações, como por exemplo a implementada onde somente mudamos variáveis, pode acontecer que a fórmula testada não permita que uma variável do modelo seja alterada. Isso acarretará que a heurística não será capaz de sugerir mudanças e entrará num loop infinito. Devemos tomar esse cuidado ao implementar e escolher a heurística a ser usada. 
Por fim, o formato de entrada é feito num arquivo texto que descreve uma estrutura de Kripke. Esse formato não é muito amigável e tende-se a tornar de difícil escrita ou entendimento conforme os exemplos aumentam. Isso é uma forma de restrição das estruturas possíveis de serem implementadas. 


\section{Capítulo 6}

\section{Conclusões}

Nosso trabalho teve como objetivo criar e implementar um algoritmo de Revisão de Crenças baseado em uma Verificação de Modelos Limitada. Para isso implementamos um algoritmo de Verificação de Modelos Limitada para ACTL usando como entrada uma estrutura de Kripke. A partir da tradução da entrada e da fórmula ACTL para uma fórmula SAT verificamos sua satisfabilidade a fim de encontrar erros ou confirmar sua validade. Quando houverem erros a serem corrigidos criamos um mecanismo de tradução reversa, transformando o resultado da verificação SAT para o formato original. Isso nos permitiu analisar os contra-exemplos e sugerir mudanças no modelo original.

Para permitir uma maior flexibilidade e eficácia, criamos um framework onde se pode criar heurísticas diferentes para se chegar as solucões da revisão. Implementamos uma heurística simples como exemplo, e criamos uma interface a ser implementado por novas heurísticas. Tudo isso resultou no código disponível em https://sourceforge.net/projects/br-bmc/.

Mostramos também que, apesar de (de Tarso Guerra Oliveira, 2016) mostrar que um processo de contração é indecidível para lógicas temporais, nossa abordagem satisfaz as restrições necessárias descritas pelo trabalho e portanto é possível executar a revisão em nosso caso.

\subsection{Considerações finais}

Uma das primeiras e principais contribuições deste trabalho foi a implementação de um algoritmo de Verificação de Modelos Limitada para ACTL e com uma entrada num formato comum como uma estrutura de Kripke. Isso permite a utilização deste mesmo algoritmo em aplicações de verificação de modelo.

Juntamente com a implementação de BMC, implementamos também uma forma de traduzir a fórmula proposicional novamente para uma estrutura de Kripke, implementando uma tradução reversa. Esta é uma contribuição original deste trabalho que permitiu analisarmos a estrutura de Kripke e sugerir mudanças no modelo utilizando o processo de BMC.

Além disso, a partir do artigo teórico (Finger e Wassermann, 2008) onde foi demonstrada a possibilidade de uso de Verificação de Modelos Limitada em Revisão de Crenças, conseguimos criar uma implementação real para o problema abordado. Essa solução cria uma nova alternativa para a execução de Revisão de Crenças. Nossa implementação também deixa em aberto um framework para se implementar diferentes estratégias para abordar a escolha das mudanças a serem feitas na revisão. Tendo em mãos os contra-exemplos e as possibilidades de mudança, qualquer um pode implementar sua própria heurística, utilizando-a no escopo desejado.

Desta forma, nosso trabalho acrescenta mais uma opção tanto no campo da Revisão de Crenças como no de Verificação de Modelos, deixando uma descrição teórica de uma solução para ambos, como uma implementação prática e com uma abordagem diversas das já existentes. 


\subsection{Trabalhos futuros}

Como descrito anteriormente, a entrada utilizada nesta implementação é uma de suas principais restrições. Portanto, uma nova forma de entrada seria muito útil para facilitar a utilização da ferramenta. Para isso, uma possibilidade é a utilização da linguagem SMV (McMillan, 1992) e possivelmente da ferramente NuSMV (Cimatti et al., 2002) para gerenciar a entrada do algoritmo, gerando a partir da linguagem formal uma estrutura de Kripke a ser utilizada no revisor. Isso acarretaria também num esforço para transformar as sugestões finais em mudanças na linguagem formal SMV.

Outra restrição que diminui as possibilidades de implementação é a dificuldade de implementar a opção de mudança para adicionar um estado. Uma solução ou uma alternativa para habilitar tal opção de mudança enriqueceria ainda mais a ideia da utilização de heurísticas.

O framework de heurísticas pode ser melhor trabalhado e testado com outros tipos de implementação, utilizando diferentes abordagens e um conjunto diverso de opções de mudança. Isso poderia agregar melhores testes e uma melhor compreensão da escolha das opções para utilizar uma heurística em um determinado escopo. 


\section{Referências Bibliográficas}

Alchourrón et al.(1985) C. E. Alchourrón, P. Gärdenfors e D. Makinson. On the logic of theory change: Partial meet contraction and revision functions. Journal of Symbolic Logic, 50:510-530. Citado na pág. 11

Bérard et al.(2001) B. Bérard, M. Bidoit, A. Finkel, F. Laroussinie, A. Petit, L. Petrucci, Ph. Schnoebelen e P. McKenzie. Systems and Software Verification. Model-Checking Techniques and Tools. Citado na pág. 8

Biere et al.(1999) Armin Biere, Alessandro Cimatti, Edmund Clarke e Yunshan Zhu. Symbolic model checking without bdds. Lecture Notes in Computer Science, 1579:193-207. Citado na pág. 9, 10

Burch et al.(1990) J. R. Burch, E. M. Clarke, K. L. Mcmillan, D. L. Dill e L. J. Hwang. Symbolic model checking: 1020 states and beyond, 1990. Citado na pág. 2, 9

Cimatti et al.(2002) Alessandro Cimatti, Edmund M. Clarke, Enrico Giunchiglia, Fausto Giunchiglia, Marco Pistore, Marco Roveri, Roberto Sebastiani e Armando Tacchella. Nusmv 2: An opensource tool for symbolic model checking. Em Computer Aided Verification, páginas 359-364. Citado na pág. 46

Clarke e Emerson(1982) Edmund M. Clarke e E. Allen Emerson. Design and synthesis of synchronization skeletons using branching-time temporal logic. Em Logic of Programs, Workshop, páginas 52-71, London, UK. Springer-Verlag. ISBN 3-540-11212-X. Citado na pág. 6

Clarke et al.(1999) Edmund M. Clarke, Orna Grumberg e Doron A. Peled. Model Checking. The MIT Press. Citado na pág. 9

de Sousa(2007) Thiago Carvalho de Sousa. Revisão de modelos formais de sistemas de estados finitos. Citado na pág. 1, 10, 29, 40, 42

de Tarso Guerra Oliveira(2016) Paulo de Tarso Guerra Oliveira. Revisão de crenças temporais. Citado na pág. 2, 13, 16, 29, 45

Finger e Wassermann(2008) Marcelo Finger e Renata Wassermann. Revising specifications with ctl properties using bounded model checking. Em SBIA '08: Proceedings of the 19th Brazilian Symposium on Artificial Intelligence, páginas 157-166, Berlin, Heidelberg. Springer-Verlag. ISBN 978-3-540-88189-6. Citado na pág. ix, 2, 7, 10, 11, 13, 15, 16, 20, 29, 41, 45

Flouris(2006) Giorgos Flouris. On belief change in ontology evolution: Thesis. AI Commun., 19 (4):395-397. ISSN 0921-7126. Citado na pág. 15

Gabbay et al.(1980) Dov Gabbay, Amir Pnueli, Saharon Shelah e Jonathan Stavi. On the temporal analysis of fairness. Em Proceedings of the 7th ACM SIGPLAN-SIGACT symposium on Principles of programming languages, POPL '80, páginas 163-173, New York, NY, USA. ACM. Citado na pág. 6 
Gärdenfors(1988) Peter Gärdenfors. Knowledge in flux: Modeling the dynamics of epistemic states. Citado na pág. 11, 12

Grumberg e Long(1994) Orna Grumberg e David E. Long. Model checking and modular verification. ACM Trans. Program. Lang. Syst., 16(3):843-871. ISSN 0164-0925. doi: 10.1145/177492.177725. URL http://doi.acm.org/10.1145/177492.177725. Citado na pág. 8

Huth e Ryan(2004) Michael Huth e Mark Ryan. Logic in Computer Science: Modelling and Reasoning About Systems. Cambridge University Press, New York, NY, USA. ISBN 052154310X. Citado na pág. 5, 6, 7, 9, 18

Lamport(1977) L. Lamport. Proving the correctness of multiprocess programs. IEEE Trans. Softw. Eng., 3(2):125-143. ISSN 0098-5589. doi: 10.1109/TSE.1977.229904. URL http://dx.doi. org/10.1109/TSE.1977.229904. Citado na pág. 8

McMillan(1992) Ken McMillan. Symbolic Model Checking - an approach to the state explosion problem. Tese de Doutorado, Carnegie Melon University, School of Computer Science. Citado na pág. 46

Penczek et al.(2000) Wojciech Penczek, Maciej Szreter, Rob Gerth e Ruurd Kuiper. Improving partial order reductions for universal branching time properties. Fundam. Inform., 43(1-4):245267. doi: 10.3233/FI-2000-43123413. URL http://dx.doi.org/10.3233/FI-2000-43123413. Citado na pág. 8

Penczek et al.(2002) Wojciech Penczek, Bozena Wozna e Andrzej Zbrzezny. Bounded model checking for the universal fragment of ctl. Fundam. Inform., 51(1-2):135-156. Citado na pág. 2, 8, $9,10,17,18$

Wassermann e Hansson(1998) Renata Wassermann e Sven Ove Hansson. Local change. Em In Fourth Symposium on Logical Formalizations of Common Sense Reasoning. Citado na pág. 15, 29

Zhang e Ding(2008) Yan Zhang e Yulin Ding. Ctl model update for system modifications. Journal of Artificial Intelligence Research, 31:113-155. Citado na pág. 2, 21 